\title{
PIASy, a nuclear matrix-associated SUMO E3 ligase, represses LEF1 activity by sequestration into nuclear bodies
}

\author{
Shrikesh Sachdev, ${ }^{1}$ Laurakay Bruhn, ${ }^{1}$ Heidemarie Sieber, ${ }^{1}$ Andrea Pichler, ${ }^{2}$ Frauke Melchior, ${ }^{2}$ \\ and Rudolf Grosschedl ${ }^{1,3}$ \\ ${ }^{1}$ Gene Center and Institute of Biochemistry, University of Munich, 81377 Munich, Germany; and ${ }^{2}$ Max-Planck Institute \\ of Biochemistry, 82152 Martinsried, Germany
}

The Wnt-responsive transcription factor LEF1 can activate transcription in association with $\beta$-catenin and repress transcription in association with Groucho. In search of additional regulatory mechanisms of LEF1 function, we identified the protein inhibitor of activated STAT, PIASy, as a novel interaction partner of LEF1. Coexpression of PIASy with LEF1 results in potent repression of LEF1 activity and in covalent modification of LEF1 with SUMO. PIASy markedly stimulates the sumoylation of LEF1 and multiple other proteins in vivo and functions as a SUMO E3 ligase for LEF1 in a reconstituted system in vitro. Moreover, PIASy binds to nuclear matrix-associated DNA sequences and targets LEF1 to nuclear bodies, suggesting that PIASy-mediated subnuclear sequestration accounts for the repression of LEF1 activity.

[Key Words: PIAS; SUMO; LEF1/TCF; nuclear matrix; PML bodies]

Received September 14, 2001; revised version accepted October 17, 2001.

The regulation of complex biological processes by a limited number of transcription factors requires the diversification and modulation of the activities of these proteins by covalent modifications and/or associations with multiple and distinct cofactors. Typically, the activities of transcription factors can be regulated by changes in protein stability, subcellular localization, and transcriptional activation or repression potential. Although the nucleo-cytoplasmic distribution of transcription factors represents the most studied form of regulation of subcellular localization, targeting of transcription factors to specific subnuclear structures may also affect their activity. The interphase nucleus is organized into different domains, including chromosome territories and the interchromatin space, also termed the nuclear matrix (for review, see Cremer and Cremer 2001). The interchromatin space contains various subnuclear structures and bodies that can be distinguished by shape, constituents, and proposed roles in cellular processes (Spector 1993; Lamond and Earnshaw 1998).

PML nuclear bodies, also termed PML oncogenic domains (PODs) or ND10, are nuclear matrix-associated spherical structures of 0.2 to $0.5 \mu \mathrm{m}$ in diameter that occur in varying numbers and sizes in most mammalian cells (for review, see Seeler and Dejean 1999; Hatta and

${ }^{3}$ Corresponding author.

E-MAIL rgross@Imb.uni-muenchen.de; FAX 49-89-2180-6949.

Article and publication are at http://www.genesdev.org/cgi/doi/10.1101/ gad. 944801 .
Fukamizu 2001; Zhong et al. 2001). The PML component of PODs was initially detected in acute promyelocytic leukemia, in which the PML gene is translocated to the retinoic acid receptor- $\alpha$ locus, generating a dominantnegative fusion protein that induces the disintegration of PODs (de The et al. 1991; Kakizuka et al. 1991). Additional evidence for the role of PML in the formation of PODs came from the analysis of fibroblasts from $P M L^{-/-}$ mice, which lack PODs and show increased cell growth (Wang et al. 1998). PML nuclear bodies appear to be heterogeneous, and they have been implicated in both positive and negative regulation of gene expression. PML promotes the localization of the transcriptional coactivator, CBP, to nuclear bodies, and in this context, enhances the transcriptional activity of nuclear receptors (Wang et al. 1998; Boisvert et al. 2001). However, PML can also interact with multiple corepressors and histone deacetylases, and the targeting of transcriptional regulators to PML nuclear bodies can also result in their inactivation (Khan et al. 2001; Wu et al. 2001). The sequestration of Daxx and Spl in PODs antagonizes the function of these transcription factors, and repression of transcription via the Mad protein also requires interaction with PML (Vallian et al. 1998; Li et al. 2000; Khan et al. 2001). Another major component of PML nuclear bodies, the Sp100 protein, interacts with heterochromatin protein 1 (HP1), establishing a connection between nuclear bodies and chromatin (Lehming et al. 1998; Seeler et al. 1998). The dynamics of PML nuclear bodies-which change in number and composition during 
the cell cycle, extracellular stress, and viral infectioncorrelate with the conjugation of PML with the small ubiquitin-like modifier 1 (SUMO1) protein (for review, see Melchior 2000; Hay 2001; Muller et al. 2001). Sumoylated PML is found exclusively in PODs; sumoylation is required for targeting of PML to mature nuclear bodies, but it is dispensable for the association of PML with the nuclear matrix (Muller et al. 1998; LallemandBreitenbach et al. 2001).

The SUMO conjugation system has been extensively studied and shows similarity with the ubiquitin conjugation system (for review, see Herschko and Ciechanover 1998; Melchior 2000; Hay 2001; Muller et al. 2001). Specifically, SUMO is activated in an ATP-dependent manner by an E1 enzyme, consisting of an Aos1/ Uba2 heterodimer (Johnson et al. 1997). Activated SUMO is transferred to a SUMO-conjugating enzyme, Ubc9, and subsequently attached to the $\varepsilon$-amino group of specific lysines of protein substrates (Johnson and Blobel 1997). Although the SUMO conjugation of substrates, such as RanGAP1, requires only E1 and E2 enzymes, this process is inefficient in comparison to sumoylation in cell extracts (Saitoh et al. 1998; Azuma et al. 2001). Thus, it is likely that the attachment of SUMO to targets also involves E3-like proteins, which confer target specificity, but have not yet been identified in the SUMO modification system. The conjugation of proteins with SUMO can also be reversed by the action of isopeptidases, allowing for a dynamic regulation of SUMO-dependent processes (for review, see Melchior 2000).

Lymphoid enhancer factor 1 (LEF1) is a member of the LEF1/TCF subfamily of HMG domain proteins that act as architectural transcription factors and nuclear mediators of Wnt signaling (for review, see Cadigan and Nusse 1997; Eastman and Grosschedl 1999; Bienz and Clevers 2000). LEF1 is unable to activate transcription on its own, but it can activate transcription in collaboration with other factors. In response to Wnt signals, $\beta$-catenin is stabilized and interacts with the $\mathrm{N}$ terminus of LEF1, thereby activating transcription of Wnt-responsive genes (Cadigan and Nusse 1997; van de Wetering et al. 1997; Hsu et al. 1998). In unstimulated cells, LEF1 can associate with the corepressor Groucho to repress Wnt-responsive genes (Levanon et al. 1998; Roose et al. 1998). In addition, LEF1 can interact with the cofactor ALY and collaborate with other transcription factors to activate enhancers of specific target genes, such as the T-cell receptor- $\alpha$ enhancer, independent of Wnt signaling (Giese et al. 1995; Bruhn et al. 1997; Mayall et al. 1997).

Although most cofactors regulate the activity of transcription factors by specific mechanisms, involving either the augmentation or inhibition of transcriptional activation, some cofactors can modulate the activity of transcription factors both positively and negatively. Protein inhibitor of activated STAT1 (PIAS1) has been identified as a cofactor that inhibits the transcriptional activation potential of STAT1 (signal transducers and activators of transcription) and augments the transcriptional activity of nuclear hormone receptors (Liu et al. 1998; Kotaja et al. 2000; Gross et al. 2001). In mammals, four
PIAS proteins (PIAS1, 3, $\mathrm{x}$, and y) have been identified (Chung et al. 1997; Liu et al. 1998). PIAS1 and PIAS3 inhibit DNA binding of STAT1 and STAT3, respectively (Chung et al. 1997; Liu et al. 1998). In contrast, PIASy represses STAT1 and androgen receptor without interfering with DNA binding (Gross et al. 2001; Liu et al. 2001). Moreover, a role for PIAS proteins in cytokine signaling was inferred from genetic experiments in Drosophila, which indicated that the orthologs dPIAS and stat92E interact functionally to regulate blood cell and eye development (Betz et al. 2001). An additional role of PIAS in the regulation of chromosome structure and function was inferred from the identification and characterization of a suppressor of position-effect variegation, Su(var)2-10, as Drosophila PIAS (Hari et al. 2001). However, it is unclear how PIAS proteins function to modulate the activity of transcription factors and regulate chromosome structure.

Here, we identify PIASy as a protein that interacts specifically with LEF1. We find that PIASy antagonizes Wnt-independent and Wnt-induced transcriptional activation by LEF1. Coexpression of PIASy with LEF1 results in the modification of LEF1 and multiple other proteins with SUMO. Furthermore, PIASy can greatly augment the sumoylation of LEF1 in an in vitro system, suggesting that PIASy functions as a SUMO E3 ligase. We show that PIASy binds to nuclear matrix DNA and targets LEF1 into nuclear bodies that colocalize with SUMO and partially colocalize with PML nuclear bodies. Thus, PIASy-mediated sequestration of LEF1 to subnuclear structures may underlie the repression of LEF1 activity.

\section{Results}

Identification of PIASy as an interaction partner of LEF1

LEF1/TCF proteins have been shown to diversify their functional properties by associating with positive cofactors, such as $\beta$-catenin and ALY, and negative cofactors, such as Groucho (for review, see Eastman and Grosschedl 1999; Bienz and Clevers 2000). To gain further insight into the regulatory mechanisms of LEF1 function, we searched for additional interaction partners of LEF1. Toward this end, we performed a yeast two-hybrid screen with a LEF-LexA fusion protein, in which the HMG domain of LEF1 had been replaced with the DNAbinding domain of LexA (Bruhn et al. 1997). One of the positive clones that interacted specifically with LEFLexA was used to screen a pre-B-cell library for the isolation of full-length cDNA clones. Sequencing of a fulllength clone, initially termed $60-7 z$, revealed that the encoded protein was identical with a member of the protein inhibitor of activated STAT family, PIASy (Liu et al. 1998). To confirm the specificity of the interaction between LEF1 and PIASy, we performed a GST pull-down experiment with an immobilized GST-PIASyN97 protein, in which the originally isolated cDNA clone, encoding the N-terminal 97 residues, was fused to a GST cDNA. Full-length LEF1 and various $\mathrm{N}$ - and C-terminal 
truncations of LEF1 were radiolabeled by in vitro translation, and their association with immobilized GSTPIASyN97 was determined relative to the binding of fulllength LEF1 (Fig. 1A,B). Deletion of the $98 \mathrm{~N}$-terminal residues of LEF1 modestly augmented the interaction with PIASyN97, and further deletions to residue 243 of LEF1 did not interfere with binding. However, C-terminal truncations to residue 340 of LEF1 diminished binding by a factor of four, and further deletion of the HMG domain virtually abolished interaction with PIASyN97. Thus, amino acids 304 to 340 within the HMG domain of LEF1 are critically required for association with the $\mathrm{N}$ terminus of PIASy in vitro.

We also examined the interaction between LEF1 and
PIASy by coimmunoprecipitation of the proteins in transfected 293T cells. Towards this end, we coimmunoprecipitated full-length LEF1 and truncated forms of LEF1 with antibodies directed against a T7 epitope that had been fused to the $\mathrm{N}$ terminus of PIASy (Fig. 1C). The coimmunoprecipitated LEF1 proteins were detected by immunoblot analysis with anti-LEF1 antiserum. Fulllength LEF1 and a truncation mutant lacking the N-terminal 166 amino acids $(\Delta \mathrm{N} 166)$ were efficiently coimmunoprecipitated from transfected cells expressing PIASy (Fig. 1C). In contrast to the GST pull-down experiments, further deletion of N-terminal residues of LEF1 to amino acid 243 modestly but consistently reduced the interaction with PIASy in vivo (Fig. 1, cf. B and C). We
Figure 1. PIASy associates with LEF1 in vitro and in vivo. (A) Schematic line diagrams of PIASy and LEF1. PIASy contains a putative chromatin-binding SAP domain, a C2HC3 RING domain (RING), and a C-terminal serinerich and acidic domain (Ser/Ac). Amino acids 1 to 97 of PIASy (PIASyN97) were sufficient for interaction with LEF1 in a yeast two-hybrid screen. LEF1 contains a $\beta$-catenin interaction domain $(\beta B D)$, a context-dependent activation domain (CAD), and a high-mobility group DNA-binding domain (HMG). Numbers below the line diagrams indicate the amino acid positions of the respective protein domains. The nuclear localization signal in PIASy and in LEF1 is indicated by a black box. The ability of $\mathrm{N}$ - or C-terminal-truncated LEF1 proteins to associate with immobilized GST-PIASyN97 was quantified by Phosphorimager analysis and is presented as a percentage relative to the binding of full-length LEF1. (B) In vitro association of LEF1 and PIASy. N- or C-terminal-truncated LEF1 proteins were in vitro translated in the presence of $\left[{ }^{35} \mathrm{~S}\right]$-methionine, resolved by SDSPAGE, and detected by fluorography. (Left) Ten percent of the input LEF1 proteins. Numbers indicate the molecular mass of protein markers in kilodaltons. (Right) LEF1 proteins bound to immobilized GST-PIASyN97. The in vitro translated LEF1 proteins did not bind to immobilized GST (data not shown). (C) In vivo association of LEF1 and PIASy. N- or C-terminaltruncated LEF1 and T7 epitope-tagged PIASy proteins were transiently expressed in 293T cells. Equivalent amounts of total cellular protein were immunoprecipitated with anti-T7 $\mathrm{mAb}$. Coimmunoprecipitated LEF1 proteins were detected by an anti-LEF1 immunoblot (right). The arrowheads indicate LEF1 proteins; the asterisks, $18-\mathrm{kD}$-larger, modified forms of LEF1. The prominent protein at $30 \mathrm{kD}$ in all lanes is IgG (right). The expression of LEF1 or T7-PIASy proteins in total cell lysates was determined by anti-LEF1 or anti-T7 immunoblots, respectively (left). PIASy $\Delta$ N93 contains a deletion of amino acids 1 to 93 in PIASy and migrates faster than full-length PIASy (bottom left). (D) Covalent modification of LEF1. LEF1 proteins in total cell lysates were detected by an anti-LEF1 immunoblot. The arrowhead indicates LEF1; the asterisk, an 18-kD-larger, modified form of LEF1.

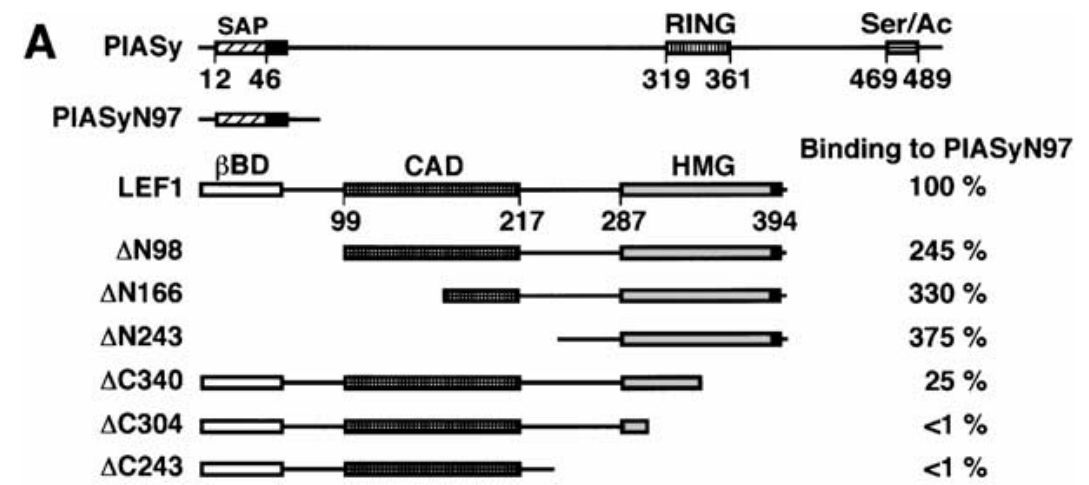

B
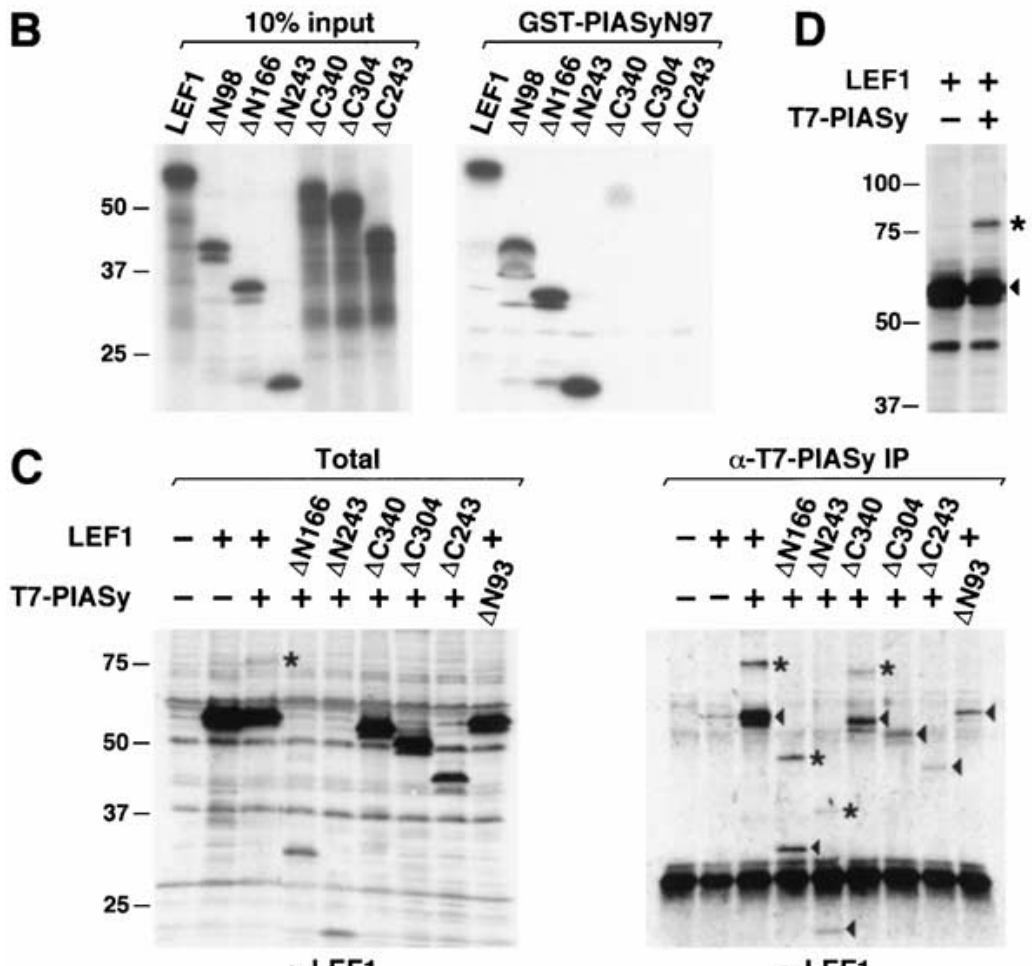

$\alpha$-LEF1

$\alpha$-T7-PIASy IP

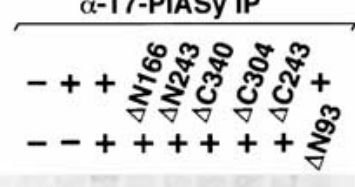

T7-PIASy



$\alpha$-LEF1

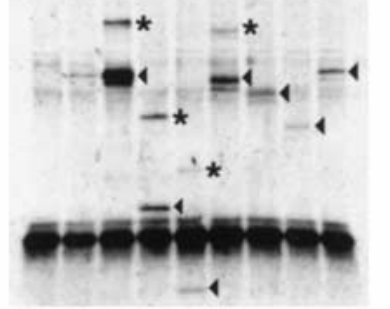

$245 \%$

$<1 \%$

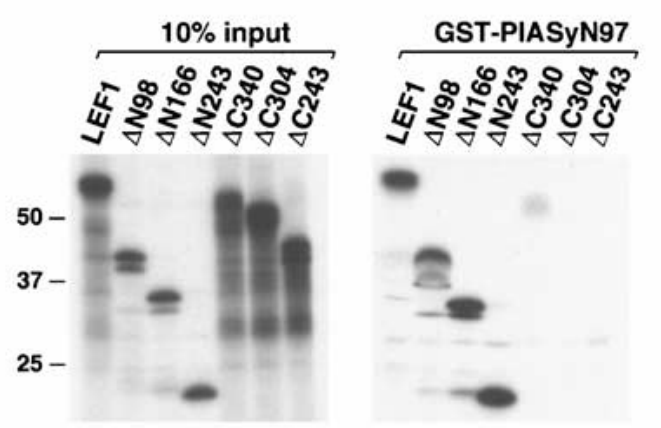


were also able to detect an association between $\mathrm{T} 7$ PIASy and LEF1-HA in reciprocal coimmunoprecipitations with anti-HA antibody (data not shown).

Deletion of the N-terminal 93 residues of PIASy, which were sufficient for the interaction with the LEFLexA fusion protein in the yeast two-hybrid screen, significantly decreased the amount of coimmunoprecipitated LEF1 protein (Fig. 1C; data not shown). This result indicates that the N-terminal domain of PIASy is necessary and sufficient for the interaction with LEF1. Similar to the GST pull-down experiments, deletion of C-terminal residues impaired the coimmunoprecipitation of LEF1 with anti-T7-PIASy antibody (Fig. 1C). Thus, the interaction of LEF1 with PIASy involves the $\mathrm{N}$ terminus of PIASy and at least two domains in LEF1, which include a major interaction domain between amino acids 304 and 340 and a minor interaction domain between amino acids 166 and 243.

In coimmunoprecipitation experiments, we consistently detected a slower-migrating form of LEF1 that corresponded to an increase in the relative molecular mass of LEF1 by $\sim 18 \mathrm{kD}$ (indicated by an asterisk). This slower-migrating form of LEF1 was also detected in immunoblots of total cell lysates from cells cotransfected with LEF1 and PIASy expression constructs, but not from cells expressing LEF1 alone (Fig. 1D). Thus, the appearance of the slower-migrating form of LEF1 is a consequence of PIASy expression rather than a consequence of coimmunoprecipitation with PIASy.

\section{PIASy-associated LEF1 is modified by SUMO conjugation}

The appearance of an 18-kD-larger, slower-migrating form of LEF1 in cells expressing both LEF1 and PIASy raised the question as to whether the coexpression of these proteins results in the covalent modification of LEF1 by conjugation with ubiquitin or with the small ubiquitin-like modifier SUMO. Toward this end, we probed three parallel blots of T7-PIASy-coimmunoprecipitated proteins with anti-ubiquitin, anti-SUMO1, or anti-SUMO2/3 antiserum and subsequently reprobed these blots with anti-LEF1 antiserum. Coimmunoprecipitated LEF1 protein did not react with the anti-ubiquitin antiserum or with the anti-SUMO1 antibody, but the slower-migrating form of LEF1 reacted with the antiSUMO2/3 antiserum (Fig. 2A; data not shown). The antiSUMO2/3 immunoblot also showed that many SUMOmodified proteins are coimmunoprecipitated from lysates of cells transfected with the T7-PIASy expression construct. In parallel immunoprecipitation experiments under more stringent conditions, we were unable to detect any SUMO2/3-modified proteins, suggesting that these proteins represent PIASy-associated proteins
A

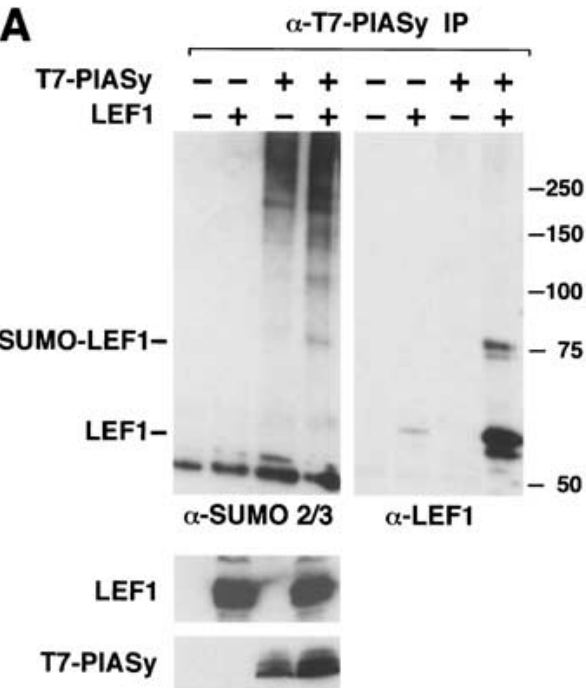

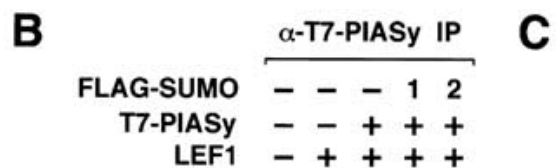

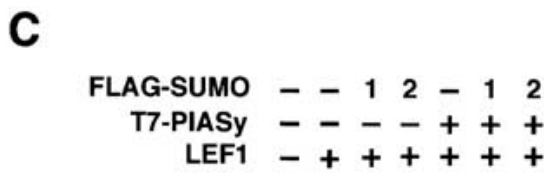

FLAG-SUMO-LEF1 = SUMO-LEF1
SUMO-LEF1

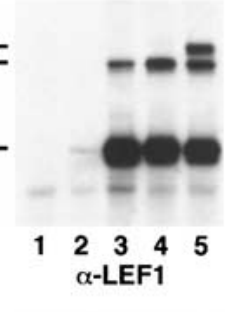

FLAG-SUMO-LEF1 SUMO-LEF1 LEF1-
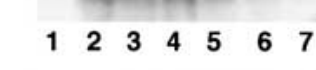

T7-PIASy

Figure 2. LEF1 is SUMO-modified in vivo. (A) PIASy associates with SUMO-modified LEF1. LEF1 and T7-PIASy were transiently expressed in $293 \mathrm{~T}$ cells. Equivalent amounts of total cellular protein were immunoprecipitated with anti-T7 mAb. Coimmunoprecipitated endogenous, SUMO-conjugated proteins were detected by an anti-SUMO2/3 immunoblot (upper left). The anti-SUMO2/3 immunoblot was stripped and reprobed with an anti-LEF1 antibody (upper right). Numbers to the right indicate the molecular mass of protein markers in kilodaltons. The expression of LEF1 or T7-PIASy proteins in total cell lysates was determined by anti-LEF1 (middle) or anti-T7 (bottom) immunoblots, respectively. (B) LEF1 is SUMO-modified in vivo. LEF1, T7-PIASy, and Flag epitope-tagged SUMO1 or SUMO2 were transiently expressed in $293 \mathrm{~T}$ cells. Equivalent amounts of total cellular protein were immunoprecipitated with anti-T7 mAb. Coimmunoprecipitated LEF1 proteins were detected by an anti-LEF1 immunoblot (top panel). The expression of LEF1 or T7-PIASy proteins in total cell lysates was determined by anti-LEF1 (middle) or anti-T7 (bottom) immunoblots, respectively. (C) LEF1, Flag epitope-tagged SUMO1 or SUMO2 and T7-PIASy were transiently expressed in 293T cells. LEF1 proteins in total RIPA buffer cell lysates were detected by an anti-LEF1 immunoblot (top). The expression of T7-PIASy proteins in total cell lysates was determined by an anti-T7 immunoblot (bottom). 
rather than SUMO-modified forms of PIASy (data not shown). Immunoblot analysis of total cell lysates with anti-LEF1 antiserum or anti-T7 antibody showed similar expression levels of LEF1 and PIASy in the transfected cells (Fig. 2A, lower panels).

To provide further evidence for SUMO modification of LEF1 in the presence of PIASy, we transfected gene constructs encoding LEF1 or T7-PIASy, together with a construct encoding Flag-tagged SUMO1 or Flag-tagged SUMO2. Immunoblot analysis of LEF1 proteins that were coimmunoprecipitated with anti-T7 antibody allowed for detection of an 18-kD-larger, slower-migrating form of LEF1 (Fig. 2B, lane 3). In the presence of FlagSUMO2, two slower-migrating forms of LEF1 were detected (Fig. 2B, lane 5). The relative increase in the molecular mass of the largest form of LEF1 is consistent with the addition of the Flag epitope to SUMO2. This slower-migrating form of LEF1 is less abundant in the presence of Flag-SUMO1 (Fig. 2B, lane 4), which might reflect a lower efficiency of conjugation with SUMO1 relative to SUMO2 and/or a lower extraction efficiency of SUMO1-conjugated LEF1 under our coimmunoprecipitation conditions. To distinguish between these two possibilities, we examined the sumoylation status of LEF1 in the absence or presence of Flag-SUMO1 or FlagSUMO2 in total cell lysates harvested in RIPA buffer (Fig. 2C). Under these stringent conditions, we could detect LEF1 modified by endogenous SUMO and by ectopically expressed Flag-SUMO1 and Flag-SUMO2. Intrigu-

ingly, expression of T7-PIASy enhanced SUMO modification of LEF1 with endogenous SUMO (cf. lanes 2 and 5) and with Flag-SUMO2 (cf. lanes 4 and 7), but it did not enhance SUMO modification of LEF1 with Flag-SUMO1 (cf. lanes 3 and 6). Taken together, these results suggest that PIASy preferentially augments modification of LEF1 with SUMO2.

The anti-SUMO2/3 immunoblot analysis of proteins that had been coimmunoprecipitated with antibodies directed against T7-PIASy suggested that PIASy is involved in the sumoylation of many proteins. To confirm the general role of PIASy in sumoylation of proteins in vivo and to examine the function of structural motifs in PIASy, we coexpressed wild-type or mutant forms of PIASy together with Flag-SUMO1 or Flag-SUMO2. As the RING motif has been implicated as an important functional determinant of ubiquitin E3 ligases (Jackson et al. 2000; Joazeiro and Weissman 2000), we examined the effects of mutations of Cys 330, 335, and 340 and His 337 in the RING domain of PIASy. In addition, we mutated Ser 470-474 in the serine-rich and acidic domain of PIASy, which bears similarity with a SUMO interaction motif in the PM-Sc175 protein (Minty et al. 2000). Immunoblot analysis of total cell lysates indicated that overexpression of wild-type PIASy increased the accumulation of Flag-SUMO-conjugated proteins relative to cells that had been transfected with the Flag-SUMO constructs alone (Fig. 3A, cf. lanes 2,3 and lanes 5,6). The mutations of the Cys/His residues in the RING domain markedly decreased the sumoylation of endogenous proteins (lanes 7,8 ), whereas the Ser mutations had only a modest effect (lanes 9,10). Immunoblot analysis with anti-T7 antibodies confirmed the similar expression of wild-type and mutant PIASy proteins (Fig. 3A, lower panel).

Finally, we sought to identify the lysine residue(s) in LEF1 that are conjugated with SUMO proteins. We searched for the presence of consensus SUMO modifica-
Figure 3. PIASy enhances SUMO-conjugation in vivo. (A) Wild-type PIASy enhances, whereas mutant PIASy proteins abrogate, SUMO-conjugation. Wild-type, RING mutant, or Ser mutant T7-PIASy proteins were coexpressed with FlagSUMO1 or Flag-SUMO2 in 293T cells. The RING mutant contains serine substitutions for cysteines 330, 335, and 340 and an alanine substitution for histidine 337 in the RING domain. The Ser mutant contains alanine substitutions for serines 470 to 474 in the Ser/Ac domain. Flag-SUMOmodified proteins from total sample buffer cell lysates were detected by an anti-Flag immunoblot (top). Numbers to the right indicate the molecular mass of protein markers in kilodaltons. The expression of T7-PIASy proteins in total cell lysates was determined by an anti-T7 immunoblot (bottom). (B) Characterization of mutant PIASy and LEF1 proteins. Wild-type or mutant LEF1 and T7-PIASy proteins were transiently expressed in 293T cells. Equivalent amounts of total cellular protein were immunoprecipitated with anti-T7 mAb. Coimmunoprecipitated LEF1 proteins were detected by an anti-LEF1 immunoblot (top). The LEF1 M2/K267R protein contains alanine substitutions for lysine 25, aspartate 26, and glutamate 27 (Hsu et al. 1998) and an arginine substitution for lysine 267 within the two consensus SUMO motifs. The expression of LEF1 or T7-PIASy proteins in total cell lysates was determined by anti-LEF1 (middle) or anti-T7 (bottom) immunoblots, respectively.
A

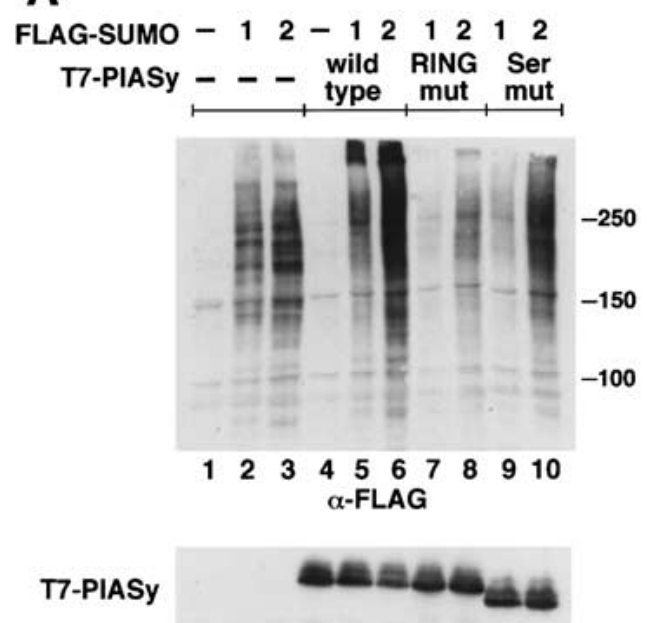

B
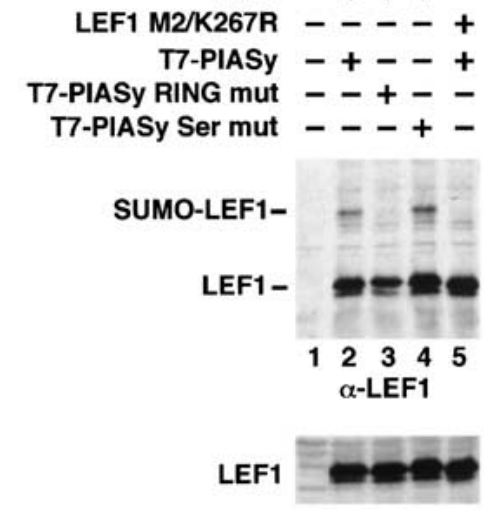

T7-PIASy
-T7-PIASy IP

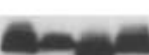


tion sites $(\psi \mathrm{KXE}$, in which $\psi$ is a large hydrophobic residue, and $\mathrm{K}$ is the lysine to which SUMO is conjugated; Rodriguez et al. 2001; Sampson et al. 2001) in LEF1 and identified two putative sites at lysine residues 25 (FKDE) and 267 (VKQE). We generated mutations in both lysines (M2/K267R) and examined their effects on sumoylation of LEF1 in the presence of PIASy. The slower-migrating form of LEF1, corresponding to SUMO-modified LEF1, was not detected, suggesting that the mutated sequences represent bona fide sumoylation sites (Fig. 3B, cf. lanes 2 and 5). Mutation of K267R alone decreased, but did not abrogate, the amount of coimmunoprecipitated SUMOLEF1, suggesting that both sites in LEF1 can be conjugated with SUMO (data not shown). Mutations of the RING domain in PIASy abrogated SUMO modification of LEF1 and slightly reduced association with LEF1 (Fig. 3B, lane 3; data not shown). In contrast, the Ser mutations did not abrogate SUMO modification or association with LEF1 (Fig. 3B, lane 4). The relative levels of LEF1 and PIASy expression were determined by immunoblot analysis of total cell lysates (Fig. 3B, lower panels). Taken together, these experiments suggest that the expression of PIASy results in extensive SUMO conjugation of multiple proteins, including LEF1. Moreover, the experiments indicate that the RING domain is an important structural determinant that is required for SUMO conjugation.

\section{PIASy stimulates SUMO conjugation of LEF1 in a reconstituted system in vitro}

The stimulatory effect of PIASy on the sumoylation of proteins raises the question as to whether PIASy is directly involved in this process. The conjugation of SUMO to target proteins shares many similarities with the ubiquitin system, although no E3 ligase for SUMOmodified proteins has yet been identified. To examine whether LEF1 can be sumoylated in the presence of E1 and E2 enzymes alone or whether PIASy facilitates this process, we used an in vitro reconstituted system with purified proteins. Incubation of recombinant LEF1 with SUMO1, the E1 enzyme Aos1/Uba2, the E2 enzyme Ubc9, and ATP did not result in significant SUMO conjugation of LEF1 (Fig. 4A, lanes 2,14). However, addition of a precipitated T7-PIASy immune complex or bacterially expressed GST-PIASy allowed for efficient and multiple conjugation of SUMO1 to LEF1 (Fig. 4A, lanes $3,15,16)$. Conjugation of SUMO1 was dependent on all other components and was not detected with PIASy protein in which the RING domain had been mutated (Fig. 4A, lane 4). The slower-migrating forms of LEF1 were identified as SUMO1 conjugates by immunoblot analysis with an anti-SUMO1 antibody (data not shown). PIASy also augmented the conjugation of SUMO2 to recombinant LEF1 in vitro (Fig. 4A, lane 12). The purity of the T7-PIASy immune complexes was examined on a silver-stained gel, showing that the T7-PIASy proteins were the predominant proteins in the immune complexes, and stoichiometric levels of additional copurifying proteins could not be detected (Fig. 4B). Taken to- gether, these data indicate that PIASy can function as a SUMO E3 ligase for LEF1. Thus, the enzymatic requirements of SUMO modification are similar to those of the ubiquitin modification process.

In LEF1, two consensus sites for SUMO conjugation were identified, one within the $\beta$-catenin interaction domain at position 25 and one immediately upstream of the HMG domain at position 267. To examine whether SUMO modifications of LEF1 alter the DNA-binding ability and/or the association with $\beta$-catenin, we generated SUMO1-modified LEF1 in vitro and performed an electrophoretic mobility shift assay with a radiolabeled LEF1-binding site. Similar DNA binding was detected with LEF1 and SUMO1-modified LEF1 (Fig. 4C). In addition, we used LEF1 and SUMO1-modified LEF1 in pulldown experiments with immobilized His-tagged $\beta$-catenin, and we visualized the bound LEF1 proteins by immunoblot analysis with anti-LEF1 antiserum. Both LEF1 and SUMO-LEF1 associated with $\beta$-catenin with similar efficiency (Fig. 4D). Together, these experiments indicate that PIASy functions as a SUMO E3 ligase for LEF1 and that SUMO modification of LEF1 does not alter its interactions with DNA and $\beta$-catenin.

\section{Repression of LEF1 activity by PIASy}

The function of LEF1 as a transcriptional regulator can be positively or negatively modulated through association with additional cofactors. In response to Wnt signaling, the association of LEF1 with $\beta$-catenin results in a marked increase in transcriptional activation (van de Wetering et al. 1997; Hsu et al. 1998). Coexpression of LEF1 and PIASy in transfected 293T cells, which lack appreciable levels of endogenous LEF1, did not result in any detectable activation of a $\mathrm{LEF}_{7}$-fos-luciferase reporter construct containing multiple LEF1-binding sites (data not shown). However, PIASy markedly reduced transcriptional activation of the reporter construct by LEF1 and $\beta$-catenin in a dose-dependent manner, but it did not reduce the basal activity of a reporter construct lacking the LEF1-binding sites (Fig. 5A; data not shown). Likewise, PIASy efficiently antagonized the activation of the reporter gene by TCF1, another LEF1/TCF family member, and $\beta$-catenin (data not shown). We also observed the repressive effects of PIASy with a reporter construct in which the natural Twin promoter was linked to the luciferase gene (Fig. 5B; Nishita et al. 2000). This PIASy-mediated repression was not observed with a mutated Twin promoter lacking the LEF1-binding sites (Fig. 5B). To determine whether PIASy antagonizes the activation potential of LEF1 in the absence of $\beta$-catenin, we used a TCR $\alpha$-fos-CAT reporter construct, which is stimulated by LEF1 in combination with Ets 1 and AML1 (Fig. 5C). PIASy repressed the activity of the TCR $\alpha$ enhancer, suggesting that PIASy antagonizes both Wnt-dependent and Wnt-independent activation by LEF1. We also confirmed that PIASy represses the activity of endogenous LEF1 in transfections of Jurkat T cells with the $\mathrm{LEF}_{7}$-fos-Luc reporter construct and $\beta$-catenin (Fig. 5D). Intriguingly, a mutant form of PIASy, in which the 
Sachdev et al.

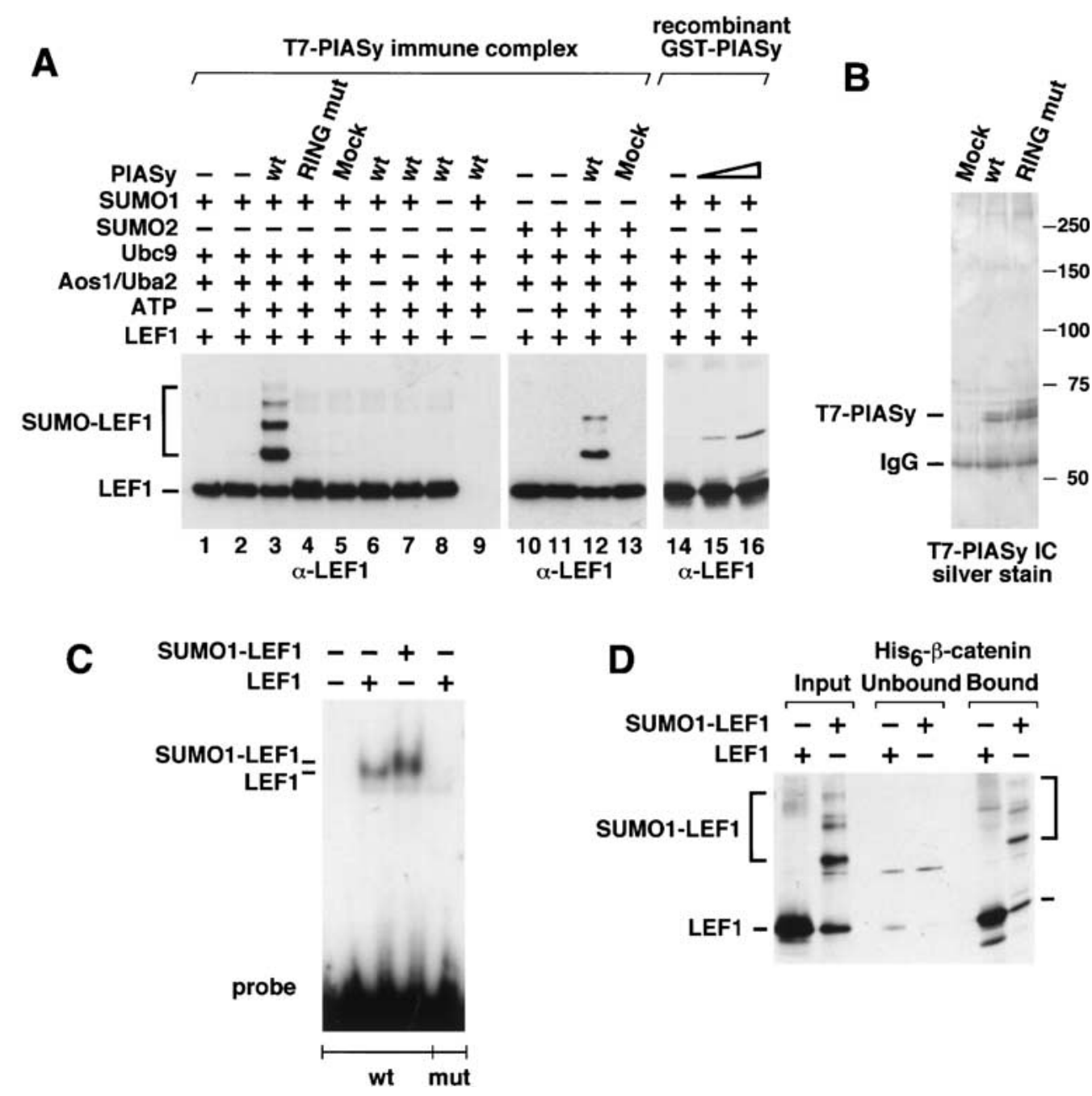

Figure 4. PIASy functions as a SUMO E3 ligase for LEF1 in vitro. (A) PIASy stimulates SUMO conjugation of LEF1. Recombinant LEF1 (25 ng) was incubated in the absence or presence of $5 \mathrm{mM} \mathrm{ATP,} 60 \mathrm{ng}$ recombinant SUMO1 or SUMO2, $150 \mathrm{ng}$ of recombinant $\mathrm{E} 1$ (Aos1/Uba2 heterodimer), $10 \mathrm{ng}$ of recombinant $\mathrm{E} 2$ (Ubc9), and $4 \mu \mathrm{L}$ of immune complex (IC)-purified wild-type (wt), RING mutant, or mock-transfected T7-PIASy for $60 \mathrm{~min}$ at $30^{\circ} \mathrm{C}$, as indicated. (Lanes 14-16) Bacterially expressed wild-type GST-PIASy (300 or 1000 ng) was used instead of IC-purified T7-PIASy, as indicated. Reactions were terminated by the addition of sample buffer. LEF1 and SUMO-modified LEF1 were resolved by SDS-PAGE and detected by anti-LEF1 immunoblots. SUMO-modified LEF1 in lanes 15 and 16 migrates slower than in lanes 3 and 12 because of different electrophoresis conditions. (B) IC-purified T7-PIASy proteins were analyzed by SDS-PAGE and detected by silver staining to determine their purity and relative abundance. (C) SUMO-modified LEF1 binds DNA. Recombinant LEF1 either was sumoylated in the presence of ATP, E1, E2, SUMO1, and wild-type PIASy as described above (SUMO1LEF1) or was treated under the same conditions without the E1 enzyme ( $\triangle E 1)$, so that LEF1 did not become sumoylated. The extent of LEF1 sumoylation was determined by an anti-LEF1 immunoblot using equivalent amounts of the $\Delta \mathrm{E} 1$ and sumoylation reactions ( $D$, input). The ability of unmodified LEF1 (25 ng) or sumoylated LEF1 (25 ng) to bind to a wt or mutated (mut) LEF1 site was determined by electrophoretic mobility shift assays. $(D)$ SUMO-modified LEF1 binds to $\beta$-catenin. The ability of equivalent amounts of unmodified or SUMO-modified LEF1 to bind to immobilized $\mathrm{His}_{6}-\beta$-catenin was analyzed by an in vitro association assay. The input, unbound, and $\mathrm{His}_{6}-\beta$-catenin-bound LEF1 was detected by an anti-LEF1 immunoblot. The recombinant LEF1 proteins did not bind to nickel beads alone (data not shown).

RING motif had been mutated, increased transcriptional activation by a factor of two, suggesting that this mutation generates a dominant-negative form of PIASy (Fig. 5D). Furthermore, the ability of the RING mutant to activate LEF1-dependent transcriptional activation suggests that endogenous PIASy might normally repress LEF1 activity. Mutation of the Ser-rich domain of PIASy only modestly reduced the extent of repression relative to wild-type PIASy (Fig. 5D). Finally, we examined the contribution of the two SUMO conjugation sites in LEF1 for PIASy-mediated repression. PIASy repressed the transcriptional activation potential of LEF1 M2/K267R almost as efficiently as that of wild-type LEF1 (Fig. 5E). Thus, the repression of LEF1 activity by PIASy requires the RING domain of PIASy, but it does not require the two consensus sumoylation sites in LEF1. 

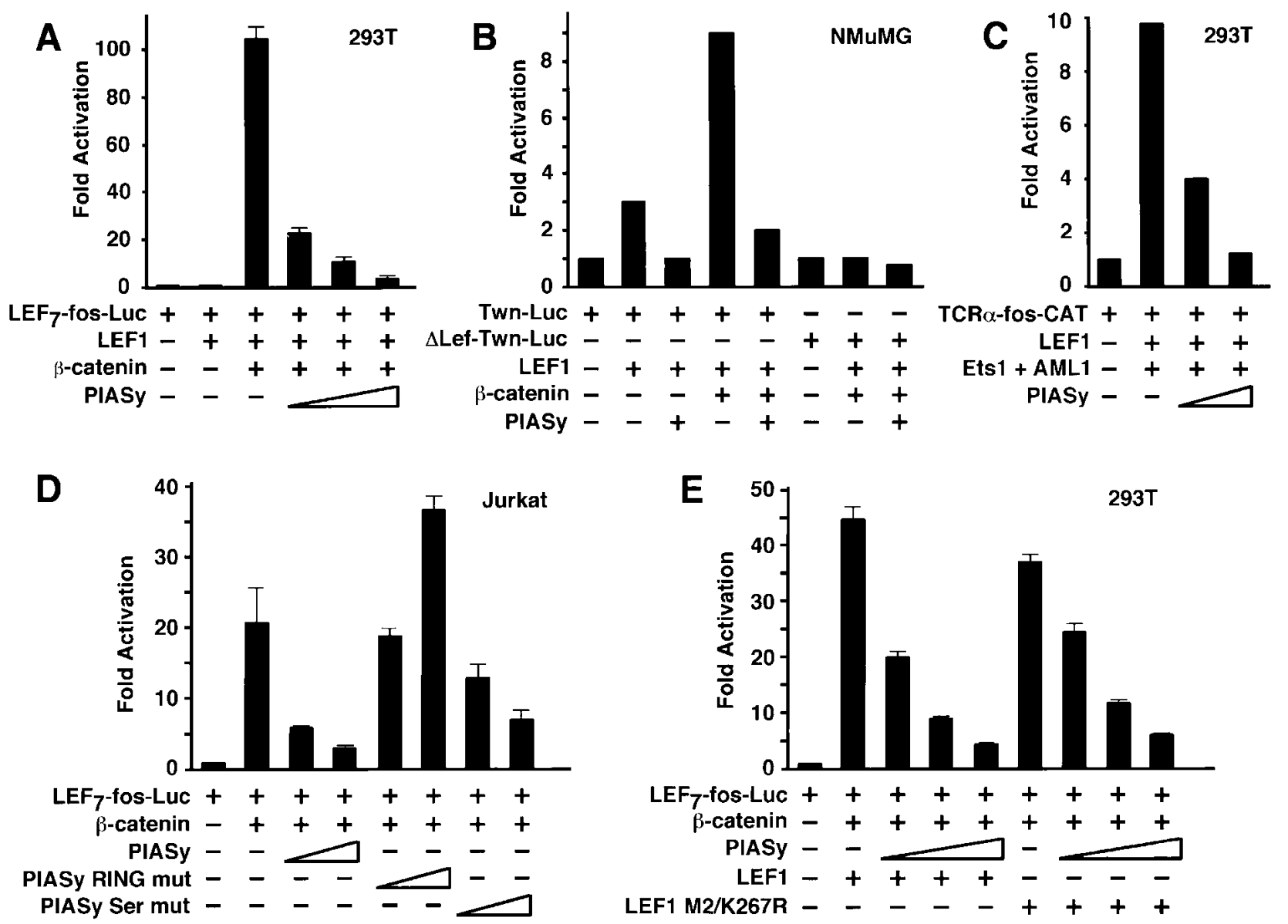

Figure 5. PIASy represses LEF1 activity. (A) PIASy represses LEF1 activity from a multimerized LEF1 reporter. 293T cells were transfected with $1 \mu \mathrm{g}$ of a LEF1 luciferase reporter construct containing multimerized LEF1-binding sites together with expression constructs encoding for $\beta$-galactosidase ( $25 \mathrm{ng}$; for normalization), LEF1 (30 ng), $\beta$-catenin ( $1 \mu \mathrm{g}$ ), or increasing amounts of T7-PIASy $(0.1,0.3$, or $1 \mu \mathrm{g})$, as indicated. For this and subsequent experiments, the levels of luciferase or CAT activity were normalized for $\beta$-galactosidase activity and are expressed as fold activation relative to the level of luciferase or CAT activity from cells transfected with the reporter construct alone. All of the transfection experiments were performed at least three times, and the results of representative experiments are shown. (B) PIASy represses LEF1-dependent Twn reporter activity. NMuMG epithelial cells were transfected with $2 \mu \mathrm{g}$ of the Twn luciferase reporter construct containing either wild-type (Twn-Luc) or mutated ( $\Delta$ LEF-Twn-Luc) LEF1-binding sites together with expression constructs encoding for $\beta$-galactosidase ( $0.5 \mu \mathrm{g}$; for normalization), LEF1 (0.5 $\mu \mathrm{g}), \beta$-catenin $(5 \mu \mathrm{g})$, or PIASy $(1 \mu \mathrm{g})$, as indicated. $(C)$ PIASy represses TCR $\alpha$ enhancer activity. 293T cells were transfected with $0.25 \mu \mathrm{g}$ of a TCR $\alpha$-CAT reporter construct together with expression constructs encoding for $\beta$-galactosidase (50 ng; for normalization), LEF1 (100 ng), Ets1, and AML1 (250 ng each) or T7-PIASy (0.3 or $1 \mu \mathrm{g}$ ), as indicated. (D) Wild-type PIASy represses endogenous LEF1 activity. Jurkat cells were transfected with $1 \mu \mathrm{g}$ of a LEF1 luciferase reporter construct containing multimerized LEF1-binding sites together with expression constructs encoding for $\beta$-galactosidase ( $0.5 \mu \mathrm{g}$; for normalization), $\beta$-catenin ( $5 \mu \mathrm{g})$, or increasing amounts of wild-type T7-PIASy (1 or $3 \mu \mathrm{g})$, RING-mutated T7-PIASy (1 or $3 \mu \mathrm{g})$, or Ser-mutated T7-PIASy (1 or $3 \mu \mathrm{g})$, as indicated. (E) Mutation of the SUMO consensus sites in LEF1 does not abrogate PIASy-mediated repression of LEF1 activity. 293T cells were transfected with $1 \mu g$ of a LEF1 luciferase reporter construct containing multimerized LEF1-binding sites together with expression constructs encoding for $\beta$-galactosidase (25 ng; for normalization), wild-type or mutant M2/K267R LEF1 (30 ng), $\beta$-catenin (1 $\mu$ g), or increasing amounts of T7-PIASy $(0.1,0.3$, or $1 \mu \mathrm{g})$, as indicated.

\section{PIASy binds to nuclear matrix attachment region DNA}

The N-terminal domain of PIASy, which is involved in interaction with LEF1, has sequence similarity with the nuclear matrix-binding protein SAF-A (Kipp et al. 2000). The region of homology between PIAS proteins and SAF-A has been termed the SAP domain and has been proposed to mediate binding to DNA sequences that are found in nuclear matrix attachment regions (MARs; Ara- vind and Koonin 2000). To examine the putative binding of PIASy to nuclear matrix-associated DNA, we performed an electrophoretic mobility shift assay with purified GST-PIASyN97 and radiolabeled oligonucleotides encompassing a wild-type or mutated MAR consensus sequence (Bode et al. 1992). Binding was detected with the wild-type MAR sequence but was significantly diminished with a mutant MAR sequence or a LEF1-binding site oligonucleotide (Fig. 6A; data not shown). 
Figure 6. PIASy binds to nuclear matrix attachment region (MAR) DNA. (A) The PIASy SAP domain binds to MAR DNA. A GST-PIASyN97 recombinant fusion protein $(0.1$ or $0.3 \mu \mathrm{g})$ encompassing the putative SAP domain was examined for its ability to bind to a wild-type (wt) or mutated (mut) MAR consensus sequence by electrophoretic mobility shift assays, as indicated. $(B)$ The N-terminal SAP domain of PIASy is required for nuclear matrix association in vivo. COS7 cells were transiently transfected with expression vectors encoding for wt T7-PIASy, a mutant T7-PIASy protein lacking its $\mathrm{N}$-terminal 93 amino acids and SAP domain but containing a heterologous NLS for nuclear targeting (T7-PIASy- 493 -NLS), or protein A-tagged Bright. At $48 \mathrm{~h}$ posttransfection, the cells were either immediately fixed (upper panels) or were processed for nuclear matrix preparations before fixation (lower panels). T7 epitope-tagged PIASy proteins were detected by indirect immunofluorescence with an anti-T7 mAb. Bright, a protein known to associate with MARs and the nuclear matrix, was detected by indirect immunofluorescence with rabbit IgG. Images were collected by confocal microscopy. The cells shown are representative of $>70 \%$ of transfected cells.

To confirm the role of the $\mathrm{N}$ terminus of PIASy in mediating the association with the nuclear matrix, we compared the retention of wild-type PIASy and a mutant form of PIASy lacking the N-terminal 93 residues encompassing the SAP domain, on nuclear matrix preparations. Because the deletion of the $\mathrm{N}$ terminus of PIASy impaired nuclear localization (data not shown), we added a heterologous nuclear localization sequence to the mutant protein. In these experiments, we used the MARbinding protein Bright as a positive control (Zong et al. 2000). As anticipated, Bright was retained in the nuclear matrix preparation (Fig. 6B). Likewise, PIASy, but not $\triangle$ N93-PIASy-NLS, was retained in the nuclear matrix preparation, suggesting that the $\mathrm{N}$ terminus of PIASy mediates the association with MARs and the nuclear matrix.

\section{PIASy targets LEF1 to nuclear bodies}

SUMO proteins have been shown to localize to specific subnuclear structures, known as PML-containing nuclear bodies (for review, see Hay 2001; Zhong et al. 2001). These structures, which contain PML, Sp100, and several other proteins, are associated with the nuclear matrix (Dyck et al. 1994; Chang et al. 1995). To examine the effects of PIASy on the subnuclear localization of LEF1, we performed two-color immunofluorescence experiments on transfected COS7 cells (Fig. 7). Confocal microscopy revealed whole nuclear staining of LEF1, whereas PIASy localized predominantly to punctate structures in the nucleus (Fig. 7A, top panel). Coexpression of LEF1 with PIASy resulted in a striking redistribution of LEF1 into punctate structures that colocalized with PIASy and could be detected in varying numbers in the nucleus (Fig. 7A, middle and bottom panels). To examine whether PIASy colocalizes with SUMO proteins, we expressed PIASy together with Flag-tagged SUMO1 or SUMO2. A complete overlap in their nuclear distribution was observed, consistent with the role of PIASy as an E3 ligase (Fig. 7B, first panel; data not shown). We also noted that expression of PIASy and Flag-SUMO2 or Flag-SUMO1 enhanced the redistribution of LEF1 into nuclear bodies (Fig. 7B, second panel; data not shown). To determine the role of SUMO conjugation of LEF1 with PIASy, we analyzed the nuclear distribution of LEF1 in the presence of the mutated RING domain PIASy protein. In addition, we examined the localization of the mutant M2/K267R LEF1 protein lacking the consensus SUMO conjugation sites, in the presence of wildtype PIASy. The mutant PIASy protein did not relocalize LEF1 to nuclear bodies, whereas the mutant LEF1 protein was efficiently targeted to nuclear bodies in the presence of wild-type PIASy (Fig. 7B, third and fourth panels). Together, these data suggest that the integrity of the RING domain, but not the sumoylation status of LEF1, is important for the sequestration of LEF1 in nuclear bodies.

Finally, we examined the identity of the PIASy- and LEF1-containing nuclear bodies by comparing the staining pattern of LEF1 or PIASy with those of the Sp100 component of PML bodies, the splicing factor SC35, and methylated histones, a hallmark of heterochromatin. Extensive colocalization of LEF1 and PIASy was only observed with Sp100 (Fig. 7C), suggesting that PIASy targets LEF1 to a subset of PML nuclear bodies.

\section{Discussion}

\section{PIASy functions as a SUMO E3 ligase}

The SUMO conjugation system shows many similarities with the ubiquitin conjugation system, including the activation of SUMO by an E1-activating enzyme and the transfer of SUMO to an E2-conjugating enzyme, which can interact directly with protein substrates through the 

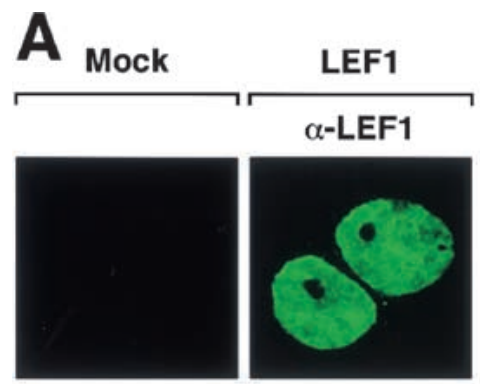
T7-PIASy

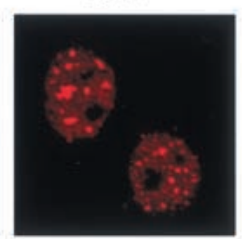

LEF1 + T7-PIASy
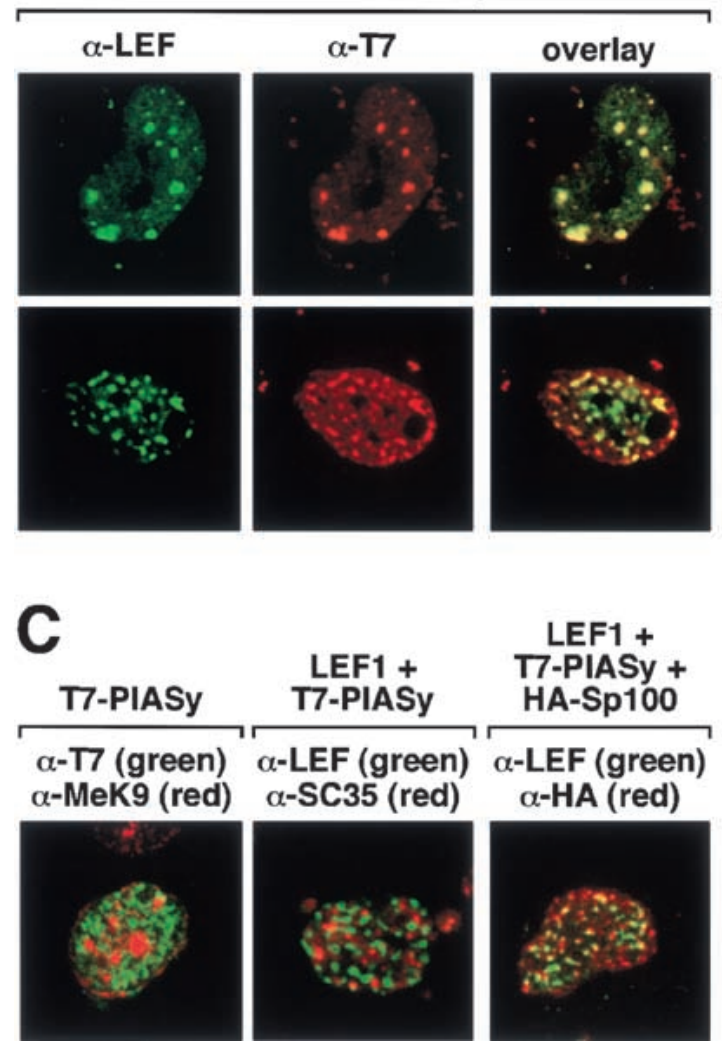

Figure 7. (A) PIASy relocalizes LEF1 to nuclear bodies. COS7 cells were either mock transfected or were transfected with expression constructs encoding for LEF1 or T7-PIASy. The intracellular distribution of the indicated proteins was detected by indirect immunofluorescence and analyzed by confocal microscopy. The intracellular distribution of LEF1 and T7-PIASy was detected with anti-LEF1 antibody and anti-T7 mAb, respectively. LEF1 alone displays a homogeneous distribution throughout the nucleus (upper, middle panel) but is detected in punctate nuclear bodies in the presence of T7-PIASy (middle, lower panels). Approximately $20 \%$ of the cells showed colocalization of LEF1 and T7-PIASy in $<20$ nuclear bodies (middle panels), whereas $>50 \%$ of the cells showed colocalization of LEF1 and T7-PIASy in multiple (>20) nuclear bodies (lower panels). (B) PIASy colocalizes with SUMO-modified proteins. COS7 cells were transfected with expression constructs encoding for wt T7-PIASy, T7-PIASy RING mut, Flag-SUMO1, Flag-SUMO2, wt LEF1, or mut LEF1 M2/K267R, as indicated. PIASy in the upper panels was detected with anti-PIASy antibody. The T7-PIASy proteins in the remaining panels were detected with anti-T7 mAb. Flag-SUMO1 was detected with anti-Flag mAb. T7-PIASy efficiently colocalized with Flag-SUMO1 or Flag-SUMO2 in nuclear bodies in $>80 \%$ of cotransfected cells (top panels; data not shown). Coexpression of Flag-SUMO1 or Flag-SUMO2 with LEF1 and T7-PIASy enhanced nuclear body localization of LEF1 by approximately twofold (second panels; data not shown). The T7-PIASy RING mutant protein displays homogeneous staining throughout the nucleus and is unable to relocalize LEF1 to nuclear bodies (third panels). The LEF1 M2/K267R mutant protein is efficiently relocalized to nuclear bodies in the presence of T7-PIASy and Flag-SUMO2 (bottom panels). (C) PIASy partially colocalizes with PML bodies. T7-PIASy, LEF1, and epitope-tagged HA-Sp100 were transfected into COS7 cells, as indicated. The intracellular distributions of T7-PIASy and dimethyllysine 9 of histone H3, a marker for heterochromatin, were detected with anti-T7 mAb and anti-MeK9, respectively (left). The distribution of LEF1 (coexpressed with T7-PIASy) and SC35, a component of the splicing machinery, was detected with anti-LEF1 and anti-SC35 mAb, respectively (center). The distribution of LEF1 (coexpressed with T7-PIASy) and HA-Sp100, a component of PML nuclear bodies, was detected with anti-LEF1 antibody and anti-HA mAb, respectively (right). LEF1 only showed a partially overlapping pattern of distribution with HA-Sp100 in PML nuclear bodies. 
consensus motif $\psi \mathrm{KXE}$ (for review, see Hershko and Ciechanover 1998; Melchior 2000; Hay 2001; Muller et al. 2001). However, target specificity, which is accomplished in the ubiquitin pathway by a third class of proteins known as the E3 enzymes, remains unclear in the SUMO modification pathway.

Three sets of data support the role of PIASy as a SUMO E3 ligase. First, an N-terminal region of PIASy encompassing the SAP domain specifically interacts with LEF1, a SUMO substrate. This region of PIASy also interacts with DNA sequences associated with nuclear matrix attachment regions and may be involved in the subnuclear sequestration of target proteins. Second, wild-type PIASy stimulates the SUMO modification of LEF1 and multiple other proteins in vivo, and it greatly stimulates SUMO conjugation of LEF1 in an in vitro system with recombinant proteins. Mutations of the RING domain in PIASy impair the sumoylation of protein substrates in vivo, and SUMO conjugation of LEF1 is not detected in the presence of the RING mutant PIASy protein in vitro, consistent with the functional importance of RING domains in the major class of ubiquitin E3 ligases (for review, see Joazeiro and Weissman 2000; Jackson et al. 2000). By analogy with the ubiquitin pathway, the RING domain of PIASy might be involved in interactions with the E2 enzyme Ubc9 and might also play a role in substrate recognition. Consistent with this notion, mutations of the RING domain markedly impair the association with LEF1 under stringent coimmunoprecipitation conditions, in which the interaction between LEF1 and wildtype PIASy is retained (data not shown). Third, PIASy extensively colocalizes with SUMO1 and SUMO2 in nuclear bodies. This localization varies with the cell cycle and cell type (data not shown), consistent with the dynamic regulation of SUMO-containing PML nuclear bodies and the regulated assembly of SUMO-modified TEL protein into nuclear bodies during the cell cycle (Everett et al. 1999; Chakrabarti et al. 2000).

\section{Role of SUMO conjugation of LEF1 and PIASy association}

The expression of PIASy results in both sumoylation and subnuclear sequestration of LEF1. Although the physiological relevance of SUMO conjugation of LEF1 remains unclear, three lines of evidence suggest that SUMO modification of LEF1 augments its association with PIASy and targeting of LEF1 to nuclear bodies. First, the ratio of SUMO-conjugated LEF1 to unmodified LEF1 is markedly increased in coimmunoprecipitation assays with T7-PIASy relative to that observed in total cell lysates. The effect of sumoylation of LEF1 on its interaction with PIASy is reminiscent of the enhancement of the association between Sp100 and HP1 by SUMO conjugation of Sp100 (Seeler et al. 1998, 2001). Second, coexpression of SUMO1 or SUMO2 with LEF1 and PIASy enhances the targeting of LEF1 to nuclear bodies. Third, the RING mutant PIASy protein, which is deficient for SUMO conjugation, is unable to sequester LEF1 in nuclear bodies and functions as a dominant-negative pro- tein in transcriptional activation assays. These results suggest that SUMO modification, nuclear body sequestration, and transcriptional repression are closely linked. Although the analysis of the LEF1 M2/K267R mutant indicates that sumoylation of LEF1 may not be a prerequisite for its association with PIASy and its subnuclear sequestration, SUMO modification of another critical target in the PIASy pathway might be required to inhibit transcription independent of SUMO modification of LEF1. Alternatively, LEF1 might be sumoylated at low levels at additional, nonconsensus SUMO conjugation sites, which cannot be easily detected in Western blots but might be sufficient for subnuclear sequestration and repression of LEF1 activity.

The function of SUMO conjugation is, with a few exceptions, still fairly obscure (for review, see Melchior 2000; Muller et al. 2001). Similar to LEF1, the p53 protein is sumoylated and mutation of the major SUMO conjugation site, K386R, does not affect p53-dependent transactivation, growth suppression, or targeting of p53 to nuclear bodies (Fogal et al. 2000; Kwek et al. 2001). However, coexpression of p53 with SUMO1 and Ubc9 or with PML3 can enhance the recruitment of p53 to nuclear bodies (Fogal et al. 2000). Thus, the recruitment of LEF1 and p53 to subnuclear structures might be the critical determinant for the regulation of these proteins, and the sumoylation may simply be a consequence of the sequestration.

PIASy-mediated targeting of LEF1 to nuclear bodies correlates well with the repression of LEF1 activity. PIASy itself is localized in nuclear bodies and the nuclear matrix, and this localization depends on the presence of the N-terminal SAP domain. The subnuclear localization of LEF1 in the presence of PIASy overlaps with a subset of PML nuclear bodies. These subnuclear structures are quite heterogenous and have been implicated in transcriptional repression, transcriptional activation, and protein degradation (for review, see Hatta and Fukamizu 2001). The protein half-life of LEF1 does not significantly change in the presence of PIASy $\left(t_{1 / 2}=13 \mathrm{~h}\right.$ without PIASy versus $t_{1 / 2}=10.2 \mathrm{~h}$ with PIASy; data not shown). Therefore, the activity of LEF1 may be repressed by targeting of LEF1 to heterochromatin or by recruitment of LEF1 into complexes containing corepressors. For example, targeting of the transcription factor Ikaros to heterochromatin has been shown to mediate the repression of Ikaros target genes (Brown et al. 1997). However, nuclear bodies containing LEF1 and PIASy do not colocalize with dimethylated histones, a hallmark of heterochromatin (Nielsen et al. 2001). PML nuclear bodies have been found to contain transcriptional corepressors, such as Smrt/N-CoR, and histone deacetylases (HDACs). Treatment of cells with trichostatin A, an inhibitor of HDACs (for review, see Yoshida and Horinouchi 1999), did not antagonize PIASy-mediated repression of LEF1 activity (data not shown). Therefore, PML components different from HDACs likely account for PIASymediated repression of LEF1 activity. All PIAS family members contain a LXXLL signature motif within the SAP domain, which is required for transrepression and 
may be recognized by as yet unidentified corepressor proteins (Liu et al. 2001).

\section{Functions of PIAS proteins in the regulation} of chromosome structure and transcription

Recently, genetic experiments in Drosophila have provided some insight into the role of PIAS proteins. The Drosophila ortholog dPIAS has been identified as a suppressor of position-effect variegation, $\mathrm{Su}(\mathrm{var}) 2-10$, and extensive genetic analysis has shown that dPIAS is involved in the regulation of diverse nuclear processes that include the condensation and inheritance of chromosomes, and the clustering of telomeres and their associations with the nuclear lamina (Hari et al. 2001). The dPIAS protein is localized in a punctate nuclear pattern, and in interphase nuclei, an association with the nuclear lamina is also observed (Hari et al. 2001). dPIAS does not colocalize with HP1 and heterochromatic regions. Thus, the nuclear expression pattern of the mammalian PIASy protein and dPIAS show many similarities. Although the primary targets of dPIAS that account for the mutant phenotypes are unknown, dPIAS is also involved in the regulation of cytokine signaling by interacting with STAT proteins (Betz et al. 2001).

Biochemical studies indicated that PIAS proteins interact directly with multiple transcription factors, including the STATs, androgen receptor, and p53, and can regulate their activities both positively or negatively (Liu et al. 1998; Kotaja et al. 2000; Gross et al. 2001; Nelson et al. 2001). In particular, PIASy antagonizes the activities of STAT1, p53, and androgen receptor (Gross et al. 2001; Liu et al. 2001; Nelson et al. 2001). PIAS1 differs from PIASy by its ability to inhibit DNA binding of STAT1 and to augment the transcriptional activation of androgen receptor (Kotaja et al. 2000; Gross et al. 2001; Liu et al. 2001). Thus, the transcriptional effects of PIAS proteins are quite diverse, and it will be important to determine whether they reflect differences in PIAS proteins or in their interaction partners.

In conclusion, our experiments provide insight into the function of PIASy as a nuclear matrix-associated protein that stimulates SUMO conjugation of LEF1. A key function of PIASy appears to be the targeting of LEF1 into nuclear bodies and the repression of LEF1 activity. The regulation of PIASy expression and activity, which may be regulated during the cell cycle, will be of great future interest. Moreover, the identification of putative PIASy-associated proteins and the identification of additional targets for PIASy-enhanced SUMO conjugation will elucidate the diverse regulatory properties of PIAS proteins and the pleiotropic phenotypes of PIAS mutations.

\section{Materials and methods}

Yeast two-hybrid screen, cDNA library screen, and constructs

A fusion protein between LEF1 and the DNA-binding domain of LexA (Giese and Grosschedl 1993) was used as "bait" to screen a yeast two-hybrid E10 murine cDNA-VP16 library (Bruhn et al. 1997). A 291-bp two-hybrid clone, clone 60, was radiolabeled by random priming and used to screen a murine thymocyte cDNA library. Sequencing of a $1.6-\mathrm{kb}$ cDNA clone, $60-7 \mathrm{z}$, identified this clone as murine PIASy. Full-length $60-7 z$ was subcloned as an XhoI-blunt insert into the SmaI site of pEVRF2-T7 to generate CMV-T7-PIASy and into the SmaI site of pGEX-2T (Pharmacia) to generate GST-PIASy. GST-PIASyN97 was constructed by subcloning the original 60 two-hybrid clone into pGEX-3X (Pharmacia) as a $S \mathrm{maI} / E c o R I$ insert. T7-PIASy $\Delta$ N93 was constructed by site-directed mutagenesis of $60-7 \mathrm{z}$ and subcloning of the resulting mutant as a SmaI/XhoI-blunt insert into the SmaI site of pEVRF3-T7. T7-PIASy $\Delta$ N93-NLS was constructed similarly, except that the insert was subcloned into the SmaI site of pEVRF3-T7-NLS. The T7-PIASy RING mutant and the T7-PIASy Ser mutants were constructed by site-directed mutagenesis of $60-7 \mathrm{z}$ and subcloning of the resulting mutated cDNAs as Xhol-blunt inserts into the SmaI site of pEVRF2-T7. Plasmids encoding for full-length and truncated LEF1 proteins have been previously described (Giese and Grosschedl 1993; Bruhn et al. 1997). LEF1 K267R-HA was constructed by sitedirected mutagenesis of pBluescript-LEF1 and subcloning of the resulting mutant into pCG-LEF1-HA as a $\mathrm{KpnI} / \mathrm{XbaI}$ insert. LEF1M2 (Hsu et al. 1998) was cloned as a BspEI/XcmI insert into pCG-LEF1 K267R-HA to generate pCG-LEF1 M2/K267R. The $\mathrm{LEF}_{7}$-fos-luciferase and the TCR $\alpha$-fos-CAT reporter plasmids, and the RSV- $\beta$-galactosidase, CMV-AML1, CMV-Ets1, CMV- $\beta$-catenin, LEF1-His ${ }_{6}$, and $\mathrm{His}_{6}-\beta$-catenin expression plasmids have been previously described (Bruhn et al. 1997; Hsu et al. 1998). Human Uba2 was PCR amplified from EST clone DKFZp434DO717 and cloned into the NheI and BgIII sites of pET11d (Novagen). Human Aos1 was PCR amplified from EST clone DKFZp434J0913 and cloned into the NheI and BamHI sites of pET28a (Novagen). Mouse Ubc9 was PCR amplified from EST clone IMAGp998A061122 and cloned into the NdeI and BamHI sites of pET23a. SUMO1 (1-97) was PCR amplified from a full-length cDNA and cloned into the NdeI and BamHI sites of pET11a (Novagen). Sequences of the oligonucleotides are available upon request. All clones were confirmed by sequence analysis and protein expression.

\section{Protein expression and purification}

The ${ }^{35}$ S-labeled full-length and truncated LEF1 proteins were in vitro translated from pBluescript KS+ (Stratagene) using rabbit reticulocyte lysate (Promega). For the bacterially expressed proteins, purification involved IPTG-induced expression in Escherichia coli BL21 gold (Stratagene). Buffers contained $1 \mu \mathrm{g} / \mathrm{mL}$ each of leupeptin, pepstatin, and aprotinin and $1 \mathrm{mM}$ DTT (or $\beta$-mercaptoethanol). Lysis buffers also contained 0.1 mM PMSF. For SUMO1 purification, bacteria lysed in $50 \mathrm{mM}$ Tris- $\mathrm{Cl}(\mathrm{pH}$ 8.0 ) and $50 \mathrm{mM} \mathrm{NaCl}$ were precleared with Q Sepharose (Sigma) and purified by gel filtration. For purification of catalytically active SUMO E1 enzyme, His-Aos1 and Uba2 were coexpressed in bacteria; lysed in $50 \mathrm{mM}$ Na-phosphate buffer (pH 8.0), 300 $\mathrm{mM} \mathrm{NaCl}$, and $10 \mathrm{mM}$ imidazole; and purified on ProBond Resin (Invitrogen), followed by molecular sieving (Superdex 200) and ion exchange chromatography (Mono Q, Pharmacia Biotech). For purification of Ubc9, bacteria were lysed in $50 \mathrm{mM}$ Na-phosphate buffer (pH 6.5) and $50 \mathrm{mM} \mathrm{NaCl}$, incubated with SP-Sepharose beads (Sigma), eluted with $50 \mathrm{mM}$ Na-phosphate buffer (pH 6.5) and $300 \mathrm{mM} \mathrm{NaCl}$, and sieved through a Superdex 200 column. All of the proteins were dialyzed against transport buffer (20 mM HEPES at pH 7.5, $110 \mathrm{mM} \mathrm{K}$-acetate, $2 \mathrm{mM}$ $\mathrm{Mg}$-acetate, and 0.5 mM EGTA) before their use in the in vitro 
sumoylation assays. For purification of GST-PIASyN97 or fulllength GST-PIASy, bacteria were lysed in $10 \mathrm{mM}$ Na-phosphate buffer (pH 7.2), $150 \mathrm{mM} \mathrm{NaCl}, 10 \mathrm{mM}$ EDTA, $2 \mathrm{mM}$ DTT, and protease inhibitor mix $15 \mu \mathrm{g} / \mathrm{mL}$ each of trypsin/chymotrypsin inhibitor, antipain, aprotinin, bestatin, and leupeptin; $0.25 \mu \mathrm{g} /$ $\mathrm{mL}$ pepstatin; and $1 \mathrm{mM}$ PMSF; Sigma) and purified on glutathione-agarose beads according to the manufacturer's instructions (Pharmacia). For purification of $\mathrm{His}_{6}-\beta$-catenin, bacteria were lysed in $20 \mathrm{mM}$ HEPES ( $\mathrm{pH} 7.5$ ), $300 \mathrm{mM} \mathrm{NaCl}, 0.2 \%$ TX-100, 10\% glycerol, $7 \mathrm{mM} \beta$-mercaptoethanol, and protease inhibitor mix and purified on Ni-NTA beads according to the manufacturer's protocol (Qiagen). Protein concentrations were determined by Bradford assay according to the manufacturer's protocol (Bio-Rad).

\section{In vitro sumoylation assays}

For immune complex (IC) purification of T7-PIASy proteins, $293 \mathrm{~T}$ cells were either mock transfected or were transfected with expression constructs encoding for wild-type T7-PIASy or T7-PIASy RING mutant. At $48 \mathrm{~h}$ posttransfection, cells were harvested in WL buffer $(50 \mathrm{mM}$ Tris-Cl at $\mathrm{pH} 8.0,400 \mathrm{mM}$ $\mathrm{NaCl}, 0.5 \%$ NP-40, 10\% glycerol, 1 mM EDTA, 1 mM DTT, protease inhibitor mix, $1 \mathrm{mM} \mathrm{NaF}$, and $0.4 \mathrm{mM}$ Na-orthovanadate). Clarified lysates ( 4 mg total cellular protein) were diluted fivefold in WL buffer lacking $\mathrm{NaCl}$, and the T7-PIASy proteins were immunoprecipitated with $5 \mu$ g of anti- $\mathrm{T} 7 \mathrm{mAb}$ and $200 \mu \mathrm{L}$ of a $50 \%$ slurry of protein G-Sepharose as described (Harlow and Lane 1988). The ICs were washed 4 times with WL buffer containing $400 \mathrm{mM} \mathrm{NaCl}$ and washed 2 times with transport buffer. The sedimented ICs were resuspended in an equal volume of transport buffer. The purity and relative abundance of the sedimented T7-PIASy ICs was determined by SDS-PAGE and silver staining and by anti-T7 immunoblots. The sumoylation assays with recombinant proteins were performed in a total volume of $20 \mu \mathrm{L}$ in transport buffer supplemented with $0.05 \%$ Tween 20, $0.2 \mathrm{mg} / \mathrm{mL}$ ovalbumin grade VI, and $1 \mathrm{mM}$ each aprotinin, leupeptin, pepstatin, AEBSF, and DTT (Sigma). Reactions were incubated for $1 \mathrm{~h}$ at $30^{\circ} \mathrm{C}$ and stopped by the addition of SDS sample buffer. The samples were resolved on a $7 \%$ polyacrylamide gel, and sumoylated LEF1 was detected by an antiLEF1 immunoblot. Concentrations of recombinant proteins were as indicated in the figure legends.

\section{Cell culture, transient transfections, and reporter assays}

293 T and COS7 cells were cultured in Dulbecco's modified Eagle medium (DMEM) supplemented with penicillin-streptomycin-glutamine (PSG) and 10\% fetal bovine serum (FBS; Invitrogen Life Technologies). NMuMG cells were cultured in DMEM supplemented with PSG, $10 \mu \mathrm{g} / \mathrm{mL}$ insulin (Sigma), and $10 \%$ FBS. Jurkat $\mathrm{T}$ cells were cultured in RPMI 1640 supplemented with PSG, $50 \mu M$-mercaptoethanol (Sigma), and 10\% FBS. 293T, COS7, and NMuMG cells were plated onto $60-\mathrm{mm}$ tissue culture plates $12 \mathrm{~h}$ before transfection and were transfected with $10 \mu \mathrm{g}$ of plasmid DNA by the calcium phosphate method (Sambrook et al. 1989). Jurkat cell transfections were performed by electroporation with $30 \mu \mathrm{g}$ of plasmid DNA as described (Hughes and Pober 1996). The total DNA concentration in each transfection experiment was kept constant by adding vector plasmid DNA. Cells were harvested 36 to 48 h posttransfection in $200 \mu \mathrm{L}$ of reporter lysis buffer, and luciferase assays were conducted according to the manufacturer's instructions (Promega). CAT and $\beta$-galactosidase assays were performed as described (Starr et al. 1996).
In vitro association assays, immunoprecipitation, and Western blot analysis

In vitro GST-PIASyN97 and $\mathrm{His}_{6}-\beta$-catenin pull-down assays were conducted essentially as described (Bruhn et al. 1997). For the in vitro $\mathrm{His}_{6}-\beta$-catenin association assays, recombinant LEF1 or SUMO-LEF1 was dialyzed against $10 \mathrm{mM}$ Tris-Cl $/ \mathrm{pH}$ 8.0 ), $50 \mathrm{mM} \mathrm{NaCl}, 10 \%$ glycerol, $1 \mathrm{mM} \mathrm{DTT}$, and protease inhibitor mix before use in the pull-down assays. For coimmunoprecipitation experiments, cells were harvested in Coimmunoprecipitation buffer (20 mM Tris- $\mathrm{Cl}$ at $\mathrm{pH}$ 8.0, $25 \mathrm{mM} \mathrm{NaCl}$, $1.5 \mathrm{mM} \mathrm{MgCl}$, 1 mM EGTA, 1\% TX-100, 10\% glycerol, $1 \mathrm{mM}$ DTT, protease inhibitor mix, $1 \mathrm{mM} \mathrm{NaF}$, and $0.4 \mathrm{mM}$ Na-orthovanadate). Equivalent amounts of total protein were precleared and immunoprecipitated with $2 \mu \mathrm{g}$ of anti-T7 mAb (Novagen) as described (Harlow and Lane 1988). For direct immunoprecipitation of target proteins, cells were harvested in RIPA buffer (10 mM Na-phosphate buffer at pH 7.2, $150 \mathrm{mM} \mathrm{NaCl}$, $1 \%$ Na-deoxycholate, $1 \%$ Triton X-100, 0.1\% SDS, 1 mM DTT, protease inhibitor mix, $1 \mathrm{mM} \mathrm{NaF}$, and $0.4 \mathrm{mM}$ Na-orthovanadate). Western blots were conducted by the ECL method according to the manufacturer's instructions (Amersham-Pharmacia), with the following antibodies and dilutions: rabbit anti-LEF1 antiserum, 1:4000; anti-T7 mAb (Novagen), 1:5000; and antiFlag M2 mAb (Sigma), 1:4000.

\section{Electrophoretic mobility shift assay}

The wild-type MAR $\left(5^{\prime}\right.$-TCTTTAATTTCTAATATATT TAGAATTC-3') or mutant MAR (5'-TCTTTAATTTCTACT GCTTTAGAATTC-3') oligonucleotides were radiolabeled with ${ }^{32} \mathrm{P}$ and gel purified on a $20 \%$ native polyacrylamide gel. The LEF1 oligonucleotides have been previously described (Hsu et al. 1998). DNA-binding reactions contained $20 \mathrm{mM}$ HEPES ( $\mathrm{pH}$ 7.9), $50 \mathrm{mM} \mathrm{NaCl}, 1 \mathrm{mM}$ DTT, 5 mM EDTA, 5\% glycerol, $2 \mu \mathrm{g}$ of BSA, $10 \mathrm{ng}$ of poly dI-dC, $5000 \mathrm{cpm}$ of radiolabeled probe, and the amount of protein indicated in the figure legends. Electrophoretic mobility shift assays were conducted essentially as described (Bruhn et al. 1997; Hsu et al. 1998).

\section{Indirect immunofluorescence, nuclear matrix preparation, and confocal microscopy}

Cells were permeabilized for $2 \mathrm{~min}$ at room temperature with $0.5 \%$ TX-100 in cytoskeletal buffer (10 mM PIPES at pH 7.1, 1 $\mathrm{mM}$ EGTA, and $3 \mathrm{mM} \mathrm{MgCl} / \mathrm{l}$ and fixed for $20 \mathrm{~min}$ with $3.2 \%$ paraformaldehyde in cytoskeletal buffer. Indirect immunofluorescence was conducted essentially as described (Zeng et al. 1997). For production of anti-PIASy antiserum, rabbits were immunized with GST-PIASyN97. Primary antibodies and dilutions used were as follows: rabbit anti-LEF1, 1:500; rabbit antiPIASy, 1:200; anti-T7 mAb (Novagen), 1:1000; anti-Flag M2 $\mathrm{mAb}$ (Sigma), 1:1000; anti-HA mAb (Roche), 1:200; anti-dimethyl lysine $9 \mathrm{H} 3$ antiserum (Nielsen et al. 2001), 1:1000; and anti-SC35 mAb (Zeng et al. 1997). Secondary antibodies used were FITC-conjugated anti-rabbit antiserum (Jackson Laboratories), 1:500; and Texas red-conjugated anti-mouse antiserum (Jackson Laboratories), 1:1000. Images were obtained on a Leica NT confocal microscope. Nuclear matrix preparations were conducted essentially as described (Cai and Kohwi-Shigematsu 1999).

\section{Acknowledgments}

We thank Dr. Juan Galceran for expert assistance in preparation of the figures and for helpful suggestions on the manuscript, 
Gergana Dobreva for the cloning of $\Delta$ N93-PIASy-NLS and assistance with nuclear matrix preparations, Dr. Walter Muranyi for assistance with confocal microscopy, and members of the Grosschedl lab for insightful discussions. We thank Dr. Thomas Jenuwein for anti-dimethyl lysine $9 \mathrm{H} 3$ antiserum, Dr. Hisato Saitoh for anti-SUMO2/3 antiserum, Dr. Stefan Stamm for antiSC35 mAb, Dr. Ken Cho for the Twin luciferase reporter constructs, Dr. Thomas Stamminger for the Flag-SUMO1 and -SUMO2 expression constructs, and Dr. Philip Tucker for the Bright and HA-Sp100 expression constructs. S.S. is a fellow of the Leukemia and Lymphoma Society of America. This work was supported by funds from the German Research Foundation (DFG).

The publication costs of this article were defrayed in part by payment of page charges. This article must therefore be hereby marked "advertisement" in accordance with 18 USC section 1734 solely to indicate this fact.

\section{Note}

While this manuscript was under review, two reports provided additional evidence that PIAS proteins function as SUMO E3 ligases. Johnson and Gupta (2001) reported that Siz1 and Siz2, two Saccharomyces cerevisiae proteins related to mammalian PIAS family members, function as E3-like factors that promote SUMO conjugation to yeast septins. Kahyo et al. (2001) reported that PIAS1 functions as a SUMO E3 ligase for p53.

\section{References}

Aravind, L. and Koonin, E.V. 2000. aSAP: A putative DNAbinding motif involved in chromosomal organization. Trends Biochem. Sci. 25: 112-114.

Azuma, Y., Tan, S.H., Cavenagh, M.M., Ainsztein, A.M., Saitoh, H., and Dasso, M. 2001. Expression and regulation of the mammalian SUMO-1 E1 enzyme. FASEB J. 15: 18251827.

Betz, A., Lampen, N., Martinek, S., Young, M.W., and Darnell, J.E. 2001. A Drosophila PIAS homologue negatively regulates stat92E. Proc. Natl. Acad. Sci. 98: 9563-9568.

Bienz, M. and Clevers, H. 2000. Linking colorectal cancer to Wnt signaling. Cell 103: 311-320.

Bode, J., Kohwi, Y., Dickinson, L., Joh, T., Klehr, D., Mielke, C., and Kohwi-Shigematsu, T. 1992. Biological significance of unwinding capability of nuclear matrix-associating DNAs. Science 255: 195-197.

Boisvert, F.-M., Kruhlak, M.J., Box, A.K., Hendzel, M.J., and Bazett-Jones, D.P. 2001. The transcription coactivator CBP is a dynamic component of the promyelocytic leukemia nuclear body. J. Cell Biol. 152: 1099-1106.

Brown, K.E., Guest, S.S., Smale, S.T., Hahm, K., Merkenschlager, M., and Fisher, A.G. 1997. Association of transcriptionally silent genes with Ikaros complexes at centrometic heterochromatin. Cell 91: 845-854.

Bruhn, L., Munnerlyn, A., and Grosschedl, R. 1997. ALY, a context-dependent coactivator of LEF-1 and AML-1, is required for TCR $\alpha$ enhancer function. Genes \& Dev. 11: 640-653.

Cadigan, K.M. and Nusse, R. 1997. Wnt signaling: A common theme in animal development. Genes \& Dev. 11:32863305.

Cai, S. and Kohwi-Shigematsu, T. 1999. Intranuclear relocalization of matrix binding sites during $\mathrm{T}$ cell activation detected by amplified fluorescence in situ hybridization. Methods 19: $394-402$.
Chakrabarti, S.R., Sood, R., Nandi, S., and Nucifora, G. 2000 Posttranslational modification of TEL and TEL/AML1 by SUMO-1 and cell-cycle-dependent assembly into nuclear bodies. Proc. Nat1. Acad. Sci. 97: 13281-13285.

Chang, K.S., Fan, Y.H., Andreeff, M., Liu, J.X., and Mu, Z.M. 1995. The PML gene encodes a phosphoprotein associated with the nuclear matrix. Blood 85: 3646-3653.

Chung, C.D., Liao, J., Liu, B., Rao, X., Jay, P, Berta, P., and Shuai, K. 1997. Specific inhibition of Stat3 signal transduction by PIAS3. Science 278: 1803-1805.

Cremer, T. and Cremer, C. 2001. Chromosome territories, nuclear architecture and gene regulation in mammalian cells. Nat. Rev. Genet. 2: 292-301.

de The, H., Lavau, C., Marchio, A., Chomienne, C., Degos, L., and Dejean, A. 1991. The PML-RAR fusion mRNA generated by the $t(15 ; 17)$ translocation in acute promyelocytic leukemia encodes a functionally altered RAR. Cell 66: 675684.

Dyck, J.A., Maul, G.G., Miller, W.H.J., Chen, J.D., Kakizuka, A., and Evans, R.M. 1994. A novel macromolecular structure is a target of the promyelocytic-retinoic acid receptor oncoprotein. Cell 76: 333-343.

Eastman, Q. and Grosschedl, R. 1999. Regulation of LEF-1/TCF transcription factors by Wnt and other signals. Curr. Opin. Cell Biol. 11: 233-240.

Everett, R.D., Lomonte, P., Sternsdorf, T., van Driel, R., and Orr, A. 1999. Cell cycle regulation of PML modificaton and ND 10 composition. J. Cell Sci. 112: 4581-4588.

Fogal, V., Gostissa, M., Sandy, P., Zacchi, P., Sternsdorf, T., Jensen, K., Pandolfi, P.P., Will, H., Schneider, C., and Sal, G.D. 2000. Regulation of p53 activity in nuclear bodies by a specific PML isoform. EMBO J. 19: 6185-6195.

Giese, K. and Grosschedl, R. 1993. LEF-1 contains an activation domain that stimulates transcription only in a specific context of factor binding sites. EMBO J. 19: 4667-4676.

Giese, K., Kingsley, C., Kirshner, J.R., and Grosschedl, R. 1995. Assembly and function of a TCR $\alpha$ enhancer complex is dependent on LEF-1-induced DNA bending and multiple protein-protein interactions. Genes \& Dev. 9: 995-1008.

Gross, M., Liu, B., Tan, J., French, F.S., Carey, M., and Shuai, K. 2001. Distinct effects of PIAS proteins on androgen-mediated gene activation in prostate cancer cells. Oncogene 20: $3880-3887$.

Hari, K.L., Cook, K.R., and Karpen, G.H. 2001. The Drosophila $\mathrm{Su}(\mathrm{var}) 2-10$ locus regulates chromosome structure and function and encodes a member of the PIAS protein family. Genes \& Dev. 15: 1334-1348

Harlow, E. and Lane, D. 1988. Antibodies: A laboratory manual. Cold Spring Harbor Laboratory Press, Cold Spring Harbor, NY.

Hatta, M. and Fukamizu, A. 2001. PODs in the nuclear spot: Enigmas in the magician's pot. Science's STKE.

Hay, R.T. 2001. Protein modification by SUMO. Trends Biochem. Sci. 26: 332-333.

Hershko, A. and Ciechanover, A. 1998. The ubiquitin system. Ann. Rev. Biochem. 67: 425-479.

Hsu, S-C., Galceran, J., and Grosschedl, R. 1998. Modulation of transcriptional regulation by LEF-1 in response to Wnt-1 signaling and association with $\beta$-catenin. Mol. Cell. Biol. 18: $4807-4818$.

Hughes, C.C. and Pober, J.S. 1996. Transcriptional regulation of the interleukin-2 gene in normal human peripheral blood $\mathrm{T}$ cells: Convergence of costimulatory signals and differences from transformed T cells. J. Biol. Chem. 271: 5369-5377.

Jackson, P.K., Eldridge, A.G., Freed, E., Fuerstenthal, L., Hsu, J.Y., Kaiser, B.K., and Reimann, J.D. 2000. The lore of the 
RINGs: Substrate recognition and catalysis by ubiquitin ligases. Trends Cell Biol. 10: 429-439.

Joazeiro, C.A. and Weissman, A.M. 2000. RING finger proteins: Mediators of ubiquitin ligase activity. Cell 102: 549-552.

Johnson, E.S. and Blobel, G. 1997. Ubc9p is the conjugating enzyme for the ubiquitin-like protein Smt3p. J. Biol. Chem. 272: 26799-26802.

Johnson, E.S. and Gupta, A.A. 2001. An E3-like factor that promotes SUMO conjugation to the yeast septins. Cell 106: $735-744$.

Johnson, E.S., Schwienhorst, I., Dohmen, R.J., and Blobel, G. 1997. The ubiquitin-like protein Smt3p is activated for conjugation to other proteins by an Aos $1 \mathrm{p} / \mathrm{Uba} 2 \mathrm{p}$ heterodimer. EMBO J. 16: 5509-5519.

Kahyo, T., Nishida, T., and Yasuda, H. 2001. Involvement of PIAS1 in the sumoylation of tumor suppressor p53. Mol. Cell 8: 713-718.

Kakizuka, A., Miller, Jr., W.H., Umesono, K., Warrell, Jr., R.P., Frankel, S.R., Murty, V. V., Dmitrovsky, E., and Evans, R.M. 1991. Chromosomal translocation $\mathrm{t}(15 ; 17)$ in human acute promyelocytic leukemia fuses RAR with a novel putative transcription factor, PML. Cell 66: 663-674.

Khan, M.M., Nomura, T., Kim, H., Kaul, S.C., Wadhwa, R., Shinagawa, T., Ichikawa-Iwata, E., Zhong, S., Pandolfi, P.P., and Ishii, S. 2001. Role of PML and PML-RAR $\alpha$ in Madmediated transcriptional repression. Mol. Cell 7: 1233-1243.

Kipp, M., Gohring, F., Ostendorp, T., van Drunen, C.M., van Driel, R., Przybylski, M., and Fackelmayer, F.O. 2000. SAFBox, a conserved protein domain that specifically recognizes scaffold attachment region DNA. Mol. Cell. Biol. 20: 74807489.

Kotaja, N., Aittomaki, S., Silvennoinen, O., Palvimo, J.J., and Janne, O.A. 2000. ARIP3 (androgen receptor-interacting protein 3) and other PIAS (protein inhibitor of activated STAT) proteins differ in their ability to modulate steroid receptordependent transcriptional activation. Mol. Endocrinol. 14: 1986-2000

Kwek, S.S., Derry, J., Tyner, A.L., Shen, Z., and Gudkov, A.V. 2001. Functional analysis and intracellular localization of p53 modified by SUMO-1. Oncogene 20: 2587-2599.

Lallemand-Breitenbach, V., Zhu, J., Puvion, F., Koken, M., Honore, N., Doubeikovsky, A., Duprez, E., Pandolfi, P.P., Puvion, E., Freemont, P., et al. 2001. Role of promyelocytic leukemia (PML) sumolation in nuclear body formation, $11 \mathrm{~S}$ proteasome recruitment, and As2O3-induced PML or PML/ retinoic acid receptor $\alpha$ degradation. J. Exp. Med. 193: 13611371.

Lamond, A.I. and Earnshaw, W.C. 1998. Structure and function of the nucleus. Science 280: 547-553.

Lehming, N., LeSaux, A., Schuller, J., and Ptashne, M. 1998. Chromatin components as part of a putative transcriptional repressing complex. Proc. Natl. Acad. Sci. 95: 7322-7326.

Levanon, D., Goldstein, R.E., Bernstein, Y., Tang, H., Goldenberg, D., Stifani, S., Paroush, Z., and Groner, Y. 1998. Transcriptional repression by AML1 and LEF-1 is mediated by the TLE/Gr corepressors. Proc. Natl. Acad. Sci. 95: 1159011595.

Li, H., Leo, C., Zhu, J., Wu, X., O'Neil, J., Park, E.J., and Chen, J.D. 2000. Sequestration and inhibition of Daxx-mediated transcriptional repression by PML. Mol. Cell. Biol. 20: 17841796.

Liu, B., Liao, J., Rao, X., Kushner, S.A., Chung, C.D., Chang, D.D., and Shuai. K. 1998. Inhibition of Stat1-mediated gene activation by PIAS1. Proc. Natl. Acad. Sci. 95: 10626-10631.

Liu, B., Gross, M., ten Hoeve, J., and Shuai K. 2001. A transcriptional corepressor of Stat1 with an essential LXXLL signa- ture motif. Proc. Nat1. Acad. Sci. 98: 3203-3207.

Mayall, T.P., Sheridan, P.L., Montminy, M.R., and Jones, K.A. 1997. Distinct roles for P-CREB and LEF-1 in TCR $\alpha$ enhancer assembly and activation on chromatin templates in vitro. Genes \& Dev. 11: 887-899.

Melchior, F. 2000. SUMO-nonclassical ubiquitin. Annu. Rev. Cell. Dev. Biol. 16: 591-626.

Minty, A., Dumont, X., Kaghad, M., and Caput, D. 2000. Covalent modification of p73alpha by SUMO-1: Two-hybrid screening with p73 identifies novel -SUMO-1-interacting proteins and a SUMO-1 interaction motif. J. Biol. Chem. 275: 36316-36323.

Muller, S., Matunis, M.J., and Dejean, A. 1998. Conjugation with the ubiquitin-related modifier SUMO-1 regulates the partitioning of PML within the nucleus. EMBO J. 17: 61-70.

Muller, S., Hoege, C., Pyrowolakis, G., and Jentsch, S. 2001. SUMO, ubiquitin's mysterious cousin. Nat. Rev. Mol. Cell Biol. 2: 202-210.

Nelson, V., Davis, G.E., and Maxwell, S.A. 2001. A putative protein inhibitor of activated STAT (PIASy) interacts with p53 and inhibits p53-mediated transactivation but not apoptosis. Apoptosis 6: 221-234.

Nielsen, S.J., Schneider, R., Bauer, U.-M., Bannister, A.J., Morrison, A., O'Carroll, D., Firestein, R., Cleary, M., Jenuwein, T., Herrera, R.E., et al. 2001. Rb targets histone H3 methylaton and HP1 to promoters. Nature 412: 561-565.

Nishita, M., Hashimoti, M.K., Ogata, S., Laurent, M.N., Ueno, N., Shibuya, H., and Cho, K.W. 2000. Interaction between Wnt and TGF- $\beta$ signalling pathways during formation of Spemann's organizer. Nature 403: 781-785.

Rodriguez, M.S., Dargemont, C., and Hay, R.T. 2001. SUMO-1 conjugation in vivo requires both a consensus modification motif and nuclear targeting. J. Biol. Chem. 276: 12654-12659.

Roose, J., Molenaar, M., Peterson, J., Hurenkamp, J., Brantjes, H., Moerer, P., van de Wetering, P., Destree, O., and Clevers, H. 1998. The Xenopus Wnt effector XTcf-3 interacts with Groucho-related transcript repressors. Nature 395: 608-612.

Saitoh, H., Sparrow, D.B., Shiomi, T., Pu, R.T., and Nishimoto, T. 1998. Ubc9p and the onjugation of SUMO-1 to RanGAP1 and RanBP2. Curr. Biol. 8: 121-124.

Sambrook, J., Fritsch, E.F., and Maniatis, T. 1989. Molecular cloning: A laboratory manual, 2nd ed. Cold Spring Harbor Laboratory Press, Cold Spring Harbor, NY.

Sampson, D.A., Wang, M., and Matunis, M.J. 2001. The small ubiquitin-like modifier-1 (SUMO-1) consensus sequence mediates Ubc9 binding and is essential for SUMO-1 modification. J. Biol. Chem. 276: 21664-21669.

Seeler, J.S. and Dejean, A. 1999. The PML nuclear bodies: Actors or extras? Curr. Opin. Genet. Dev. 9: 362-367.

Seeler, J.S., Marchio, A., Sitterlin, D., Transy, C., and Dejean, A. 1998. Interaction of SP100 with HP1 proteins: A link between the promyelocytic leukemia-associated nuclear bodies and the chromatin compartment. Proc. Natl. Acad. Sci. 95: 7316-7321.

Seeler, J.S., Marchio, A., Losson, R., Desterro, J.M., Hay, R.T., Chambon, P., and Dejean, A. 2001. Common properties of nuclear body protein SP100 and TIF1 $\alpha$ chromatin factor: Role of SUMO modification. Mol. Cell. Biol. 21: 3314-3324.

Spector, D.L. 1993. Macromolecular domains within the cell nucleus. Annu. Rev. Cell. Biol. 9: 265-315.

Starr, D.B., Matsui, W., Thomas, J.R., and Yamamoto, K.R. 1996. Intracellular receptors use a common mechanism to interpret signaling information at response elements. Genes \& Dev. 10: 1271-1283.

Vallian, S., Chin, K.V., and Chang, K.S. 1998. The promyelo- 
cytic leukemia protein interacts with Spl and inhibits its transactivaton of the epidermal growth factor promoter. Mol. Cell. Biol. 18: 7147-7156.

van de Wetering, M., Cavallo, R., Dooijes, D., van Beest, M., van Es, J., Loureiro, J., Ypma, A., Hursh, D., Jones, T., Bejsovec, A., et al. 1997. Armadillo coactivates transcription driven by the product of the Drosophila polarity gene dTCF. Cell 88: 789-799.

Wang, Z.G., Delva, L., Gaboli, M., Rivi, R., Giorgio, M., CordenCardo, C., Grosveld, F., and Pandolfi, P.P. 1998. Role of PML in cell growth and the retinoic acid pathway. Science 279: $1547-1551$.

Wu, W.-S., Vallian, S., Seto, E., Yang, W.-M., Edmondson, D., Roth, S., and Chang, K.-S. 2001. The growth suppressor PML represses transcription by functionally and physically interacting with histone deacetylases. Mol. Cell. Biol. 21: 22592268.

Yoshida, M. and Horinouchi, S. 1999. Trichostatin and leptomycin: Inhibition of histone deacetylation and signal dependent nuclear export. Ann. NY Acad. Sci. 886: 23-36.

Zeng, C., Kim, E., Warren, S.L., and Berget, S.M. 1997. Dynamic relocation of transcription and splicing factors dependent upon transcriptional activity. EMBO J. 16: 1401-1412.

Zhong, S., Salomoni, P., and Pandolfi, P.P. 2001. The transcriptional role of PML and the nuclear body. Nat. Cell Biol. 2: E85-E90.

Zong, R.T., Das, C., and Tucker, P.W. 2000. Regulation of matrix attachment region-dependent, lymphocyte-restricted transcription through differential localization within promyelocytic leukemia nuclear bodies. $E M B O$ J. 19: $4123-4133$. 


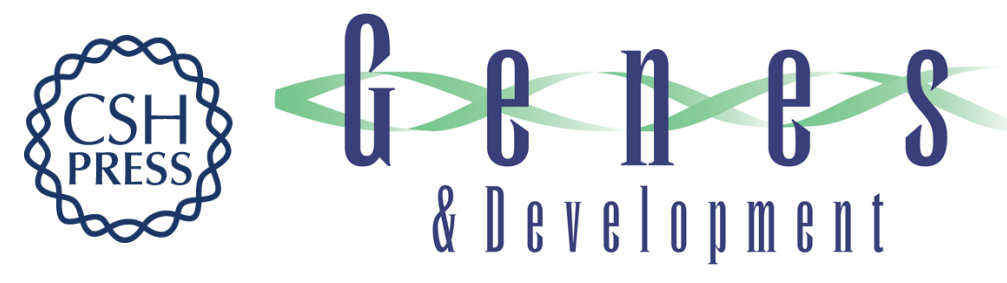

\section{PIASy, a nuclear matrix-associated SUMO E3 ligase, represses LEF1 activity by sequestration into nuclear bodies}

Shrikesh Sachdev, Laurakay Bruhn, Heidemarie Sieber, et al.

Genes Dev. 2001, 15:

Access the most recent version at doi:10.1101/gad.944801

Related Content

References

License

Email Alerting Service

\section{SUMO System in Full}

Sci. STKE January , 2002 2002: tw1

This article cites 69 articles, 36 of which can be accessed free at: http://genesdev.cshlp.org/content/15/23/3088.full.html\#ref-list-1

Articles cited in:

http://genesdev.cshlp.org/content/15/23/3088.full.html\#related-urls

Receive free email alerts when new articles cite this article - sign up in the box at the top right corner of the article or click here.

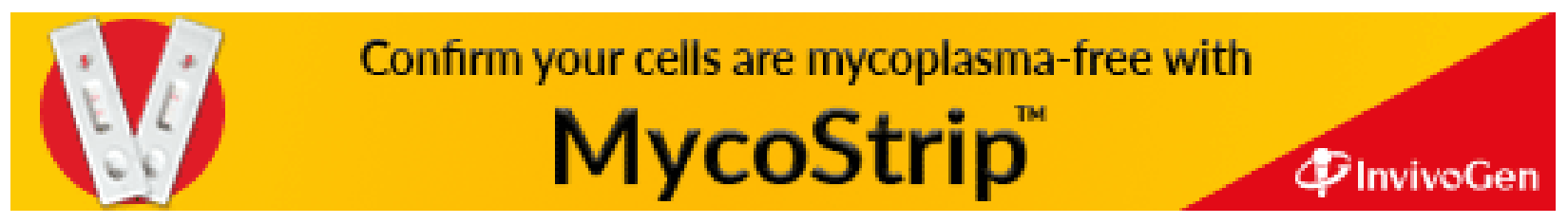

